\title{
Weather and Road Geometry Impact on Longitudinal Driving Behavior: Exploratory Analysis Using an Empirically Supported Acceleration Modeling Framework
}

\author{
Samer H. Hamdar* \\ Assistant Professor \\ Department of Civil and Environmental Engineering \\ Center for Intelligent Systems Research \\ The George Washington University \\ Science and Engineering Hall \#3810 \\ $80022^{\text {nd }}$ Street, NW \\ Washington, DC 20052, USA \\ Email: hamdar@gwu.edu \\ Phone: (202) 994-6652 \\ Fax: (202) 994-0127 \\ Lingqiao Qin \\ Graduate Student \\ Department of Civil and Environmental Engineering \\ Traffic Operation and Safety Laboratory \\ University of Wisconsin - Madison \\ Engineering Hall \#1249 \\ 1415 Engineering Drive \\ Madison, WI 53706, USA
}

\author{
Alireza Talebpour \\ Assistant Professor \\ Zachry Department of Civil Engineering \\ Texas A\&M University \\ CVLB \# 301E \\ 3136 TAMU \\ College Station, TX 77843, USA
}

January the $22^{\text {nd }}, 2016$

Submitted for publication at the "Journal of Transportation Research, Part C: Emerging Technologies" 


\title{
Weather and Road Geometry Impact on Longitudinal Driving Behavior: Exploratory Analysis Using an Empirically Supported Acceleration Modeling Framework
}

\author{
S. H. Hamdar* (hamdar@gwu.edu), L. Qin and A. Talebpour
}

\begin{abstract}
The objective of this paper is to quantify and characterize driver behavior under different roadway geometries and weather conditions. In order to explore how a driver perceives the rapidly changing driving surrounding (i.e. different weather conditions and road geometry configurations) and executes acceleration maneuvers accordingly, this paper extends a Prospect Theory based acceleration modeling framework. A driving simulator is utilized to conduct 76 driving experiments. Foggy weather, icy and wet roadway surfaces, horizontal and vertical curves, and different lane and shoulder widths are simulated while having participants driving behind a yellow cab at speeds/headways of their choice. After studying the driving trends observed in the different driving experiments, the extended Prospect Theory based acceleration model is calibrated using the produced trajectory data. The extended Prospect Theory based model parameters are able to reflect a change in risk-perception and acceleration maneuvering when receiving different parameterized exogenous information. The results indicate that drivers invest more attention and effort to deal with the weather challenges (statistically significant changes in behavior) compared to the effort to deal with the road-geometry conditions. Moreover, the calibrated model is used to simulate a highway segment and observe the produced fundamental diagram. The preliminary results suggest that the model is capable of capturing driver behavior under different roadway and weather conditions leading to changes in capacity and traffic disruptions.
\end{abstract}




\section{Weather and Road Geometry Impact on Longitudinal Driving Behavior: Exploratory Analysis Using an Empirically Supported Acceleration Modeling Framework}

S. H. Hamdar* (hamdar@gwu.edu), L. Qin and A. Talebpour

Keywords: Car Following; Driving Simulator; Prospect Theory; Road Geometry; Safety; Weather. 
3 Figure 1 Schematic of Prospect Theory Based Acceleration Model.

31

$4 \quad$ Figure 2 (a) Raw Data of Speed Profile Selected for the Lead Vehicle Based on NGSIM Data

5 (FHWA, 2005), (b) Speed Profile of the Lead Vehicle Defined in the Driving Simulator. 32

6 Figure 3 (a) Jersey Barrier, (b) Undivided Road, (c) 9ft Wide Lane with Metal Barrier, (d) 10ft

7 Wide Lane with Metal Barrier, (e) No Hard Shoulders, (f) 3ft Wide Hard Shoulder, (g)

8 Mountainous Terrain, and (f) Rolling Terrain. 33

9 Figure 4 Visibility Distance (a) 65.62ft, (b) 164ft, (c) 328ft, and (d) 656.2ft...................... 34

10 Figure 5 Minimum Time-To-Collision and Maximum Deceleration of the Follower. ............... 35

11 Figure 7 Two Examples of Drivers' Acceleration behavior in Moderately Challenging (a), and

12 Extremely Challenging (b) driving conditions.

13 Figure 9 Simulated Flow Density Diagrams Based on the Average Calibrated Acceleration

14 Model Parameters in Normal (a), Moderately Challenging (b), and Challenging (c) Driving 


\section{List of Tables}

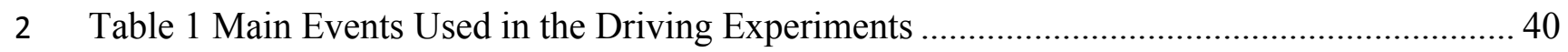

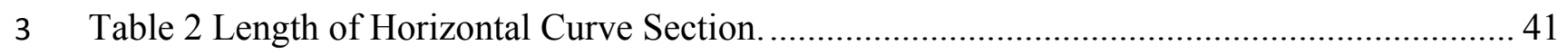

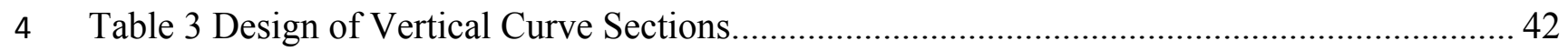

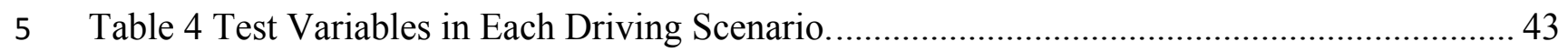

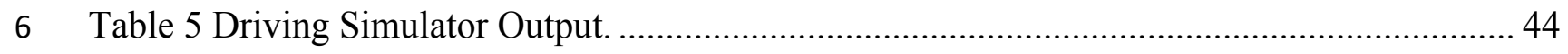

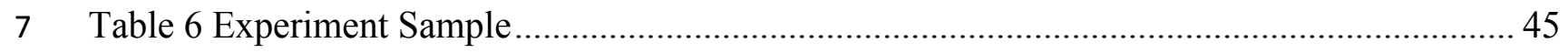

8 Table 10 Cross Comparison of Dependent and Independent Variables. ........................................ 49 


\title{
Weather and Road Geometry Impact on Longitudinal Driving Behavior: Exploratory Analysis Using an Empirically Supported Acceleration Modeling Framework
}

\author{
S. H. Hamdar*, L. Qin and A. Talebpour
}

\subsection{INTRODUCTION AND MOTIVATION}

Environmental conditions have been identified to have major impacts on driver behavior. Examples of different environmental conditions are weather-related and roadway geometryrelated factors. For instance, it has been shown that reduced visibility has a substantial impact on traffic flow dynamics (Hoogendoorn et al. (2010) while the geometry of the road layouts leads to changes in driving behavior (McLean (1981). Moreover, weather condition and road geometry are the two congestion and crash triggering factors. Empirical evidence suggests that the likelihood of rear-end crashes increases during abnormal weather or at accident prone sections (Brackstone, et. al., 2009, Winsum, 1999; Knuiman et al., 1993; Karlaftis and Golias, 2002; Polus et al., 2005). However, little effort has been made to quantify their effects on driving behavior (in the micro scale) and congestion and safety (in the macro scale). Therefore, more detail behavioral bases studies are required to describe the driver behavior in different weather and roadway conditions.

Driver behavior is subject to change according to the surrounding environment. While it is expected that different driving environments impose different changes to the driving behavior of an individual, the magnitude of deviation from normal driving behavior varies among drivers. Comprehensive study of the effect of certain driving environments on driving behavior has been presented in the literature (Brackstone et al., 2009); however, little effort has been presented to quantify the effects of different weather conditions and road geometrical configuration on driving behavior. The main objective of this paper is to explore how a driver perceives the dynamic changing driving surroundings (i.e. different weather conditions and road geometrical configurations) and executes acceleration maneuvers accordingly. Specifically, this study presents an effort to quantify the changes in drivers' car-following behavior under different roadway geometries and weather conditions. Accordingly, this study presents an extension to the Prospect Theory based car-following model of Hamdar et al. (2008, 2015). Prospect theory) is commonly considered as one of the most powerful descriptive theories of human decisionmaking. Hamdar et al. (2008) has first put forward an acceleration model, which adopts Prospect Theory to reflect the psychological and cognitive aspects of the decision making process. In this Prospect Theory based acceleration model, time is divided into different acceleration instances, and at each time instance, driver may accelerate, decelerate or keep his or her current speed. In other words, drivers make decisions on acceleration choices, and their choices are based on an evaluation of gains and losses. This paper builds on this acceleration model that translates this utility-based concept into longitudinal driving behavior. The presented model extends the current Prospect Theory logic by considering the effect of the external driving environment while keeping the adopted probabilistic nature of human judgment. A driving simulator is used to test individual driving behavior in different environmental situations and then use the data obtained from the driving experiments to calibrate the micro acceleration model. 
The structure of the remainder of this paper is as follows. First a background review on the effects of weather and road geometry on driver behavior is presented. This section is followed by the modeling framework and the related parametric sensitivity analysis. Experimental setup and data collection procedures are presented next followed by a thorough numerical analysis. The numerical results including the calibration results are presented next. The concluding remarks and the future research directions are presented last.

\subsection{BACKGROUND}

This section presents a review of the literature focused on the impact of different weather and road geometry characteristics on driver behavior. Note that this section does not provide any background on car-following behavior and microscopic simulation models. A comprehensive study of these models can be found at Hamdar et al. (2008, 2015) and Talebpour et al. (2011).

\subsection{Weather}

Multiple studies have focused on the statistical relationships between different traffic measures and different surrounding weather conditions. The overall findings of these macro level studies denote that visibility impairment, precipitation, and temperature extremes may affect driver behavior and vehicle maneuverability. Chen et al. (1995) found that weather and road surface conditions bring about some differences in car-following behavior. Based on recorded traffic data, Ibrahim and Hall (1994) found that free-flow speed reduces $1.9 \mathrm{mph}$ in light snow, 3.1 to $6.2 \mathrm{mph}$ in heavy rain, and 23.6 to $31 \mathrm{mph}$ during heavy snow. Liang et al. (1998) conducted a study to investigate the impact of visibility on speed. Through data collection, they found that average speed reduces $11.9 \mathrm{mph}$ during snow events.

Another group of studies have focused on the concepts and theories of car following to understand drivers' car following behavior, their headway selection and how the choice of headway affects safety (Brackstone, et. al., 2009, Winsum, 1999). It was suggested that drivers' car following behavior can be affected in dense fog resulting from obscure scenery (Evans, 2004). Evans (2004) also observed that drivers tended to follow the lead vehicles much closer from the fear of losing a reference when driving in foggy weather. Hawkins (1988) reported a significant increase in distance headways when visibility distance was $150 \mathrm{~m}$. Van Der Hulst et al. (1998) studied driving behavior in fog with a visibility distance of $150 \mathrm{~m}$. They noted that due to the difficulty in anticipation, drivers increase time headway under low visibility conditions. They also found that drivers' reactions to decelerations of the leader were very accurate even at low visibility levels. Broughton et al. (2007) employed a high-fidelity driving simulator to measure the car-following behavior under three visibility conditions. Two distinctive driving styles were identified in their studies: laggers and non-laggers driving styles; the laggers stopped following the leader within visible distances and instead dropped back to some larger distance headways, accompanied by increases in speed variability, whereas the non-laggers remained in a true car following mode with a visible leader ahead of them. Hoogendoorn et al. (2010) also conducted a set of driving simulation experiments and suggested that fog led to a decrease in speed as well as in acceleration rate. A substantial increase in distance to the lead vehicle was also observed in the experiments. 
The friction coefficient of the road surface, which influences vehicle's maneuverability, has been widely studied. Perrin and Martin (2002) analyzed traffic flow in Salt Lake Valley, Utah during winter. The results indicated that start-up delays on snowy pavement and wet pavement was $23 \%$ and 5\% higher, respectively, than the delays observed on dry pavement. As friction and precipitation types are highly correlated, Wu et al. (2009) presented a novel car-following model according to the relationship between vehicle deceleration and passenger comfort levels. In this model, the friction coefficient between vehicles and road surface is considered and experiments with this model showed high compatibility with real-life observations. Wallman et al. (1997) found that average speed reduces by $10 \%$ to $30 \%$ in icy and snowy weather conditions respectively. Tanaka et al. (2010) studied the influence of different road surfaces through carfollowing platoon experiments and they discovered a significant difference in driving behavior between icy and dry roadway surfaces. In addition, safe driving in adverse weather conditions also requires full detection of pavement markings. Retro-reflectivity of pavement markings varies as weather condition changes. Zwahlen et al. (1995) stated that obliteration of pavement markings heavily influences drivers' detection distances and thus affect their perception and behavior.

\subsection{Road Geometry}

Roadway layouts, including lane and shoulder width, median existence, horizontal and vertical alignment, also have considerable impact on driving behavior. Roadway geometry affects drivers' perception of driving environment and therefore influences their driving behavior (Janssen et al., 2006). Several studies showed that crash rate were associated with roadway design (Knuiman et al., 1993; Karlaftis and Golias, 2002; Polus et al., 2005). However, only few studies directly investigated the effects of a specific roadway design elements on driving behavior through controlled manipulations (Martens et al., 1997; Stamatiadis et al., 2007). In this paper and based on the above studies, horizontal and vertical alignments, lane width, shoulder widths, and median existence are considered as the geometric features of interest. Note that in this study, a roadway feature at a given candidate location is considered deficient if its value at that location is less than the recommended design value and criteria according to the AASHTO Green Book (2001).

\subsubsection{Horizontal Alignments}

Different road characteristics such as road curvature and gradient affect driving behavior differently, as suggested by Rockwell (1972). Andueza (2000) developed a model to estimate vehicular speed on curves and tangents of roads. The study found that drivers' choice of speed within horizontal curves highly depended on the roadway features before the start point of the curve. McLean (1981) studied the influences of rural road alignment on drivers' speed selection behavior by collecting free-flow speed data at 120 curves with approach tangent sites on twolane rural highways. Their analysis suggested that the observed 85 th percentile car speeds were influenced by the desired speed. Bonneson et al. (2007) investigated the effects of horizontal curves on driver behavior on rural two-lane highways. They proposed several criteria for selecting curve advisory speed. 
In addition to speed, crash rate has been also investigated in this context. Significant positive correlation has been identified between the road curvature and crash rates (Shankar et al., 1996). A number of different indicators have been adopted to study the impact of road geometric features on driving behavior. These indicators are summarized as follows:

- Bend numbers per kilometer (Barker, et al. 1999, Shankar, et al, 1995, Shankar, et al, 1996)

- Percentage of bend length to road length (Shankar, et al, 1996)

- Maximum and minimum radius of curvature (Shankar, et al, 1996)

- Cumulative absolute angle turned through per kilometer (Hughes, et al, 1996, Walmsley, et al. 1998)

Furthermore, Crashes on horizontal curves have been recognized as a considerable safety problem for many years. Zegeer et al. (1990) conducted a study on two-lane rural roads to determine how horizontal curve features affect roadway crashes. They concluded that through widening lanes or shoulders on curves, crashes can be radically reduced by as much as $33 \%$. Several other studies examined the relationship between specific levels of horizontal curve and crash rate. These studies resulted in the following conclusions where crash rate tends to increase for,

1) Curves of radii less than 1312ft (McLean, 1981; Choueiri and Lamm, 1987; and Krebs and Kloeckner, 1977),

2) Curves of radii less than $1968 \mathrm{ft}$ on rural two-lane roads (Choueiri and Lamm, 1987; Johnston, 1982), and

3) Curves over 3 degrees (1910ft) (Cirillo and Council, 1986).

\subsubsection{Vertical Alignment}

Yang and Peng (2010) identified the road gradient as an exogenous disturbance of longitudinal driving behaviors in an error-able car-following model. Mullins and Keese (1961) also suggested that rear-end accidents were common at vertical curve locations where unfavorable sight conditions existed. Lefeve (1953) investigated driver behavior on two lane rural highways with vertical curves, where the minimum sight distances ranged between 150 and $500 \mathrm{ft}$. It was observed that drivers invariably reduced the speeds as they approached vertical curves with short sight distances. It was also found that speeds at the vertical curves (regardless of the sight distance) appeared to be determined by present operating speeds. According to this study, roadway crash rate was much higher on sag curves than on crest curves. Glennon (1985) noted that crash rate at grade sections were much higher than crash rate at level sections. Their findings showed that crash rate is higher at steep gradients and down-hill sections.

\subsubsection{Lane Width}

The effect of lane width on traffic flow efficiency as well as safety implications has been investigated for many years. Harwood et al. (1990) suggested that the roadway capacity would drop when the width of traffic lanes is below $12 \mathrm{ft}$. Specifically, $11 \mathrm{ft}$ lanes have $3 \%$ less capacity than $12 \mathrm{ft}$ lanes; $10 \mathrm{ft}$ lanes have $7 \%$ less capacity than $12 \mathrm{ft}$ lanes; $9 \mathrm{ft}$ lanes streets have $10 \%$ less capacity than $12 \mathrm{ft}$ lanes. Narrower lanes are perceived as less tolerant and less secure. This led drivers to adopt speed control to avoid dangerous or risky situations (Summala, 1996). De Waard (1995) noted that driving on a narrow lane requires greater mental effort than driving on a wide 
lane, because drivers need to keep vehicles within the lane. Yagar and Van (1983) reported 1.1 mph reduction in average speed for every 1 foot reduction in lane width. Likewise, Heimbach et al. (1983) found that during off-peak hours, if lanes narrowed by $1 \mathrm{ft}$, speed would tend to reduce $0.6 \mathrm{mph}$, when other factors are held constant. They showed that during peak hours, speed decreases by $1 \mathrm{mph}$ per foot of lane width. Fitzpatrick et al. (2000) stated that 1 foot increase in lane width would result is $2.9 \mathrm{mph}$ increase in average speed. Vey and Ferreri (1968) also found a direct relationship between lane width and speed: higher speeds were observed for $11 \mathrm{ft}$ lanes compare to $10 \mathrm{ft}$ lanes.

Besides the impact of lane width on driving behavior and speed selection, lane width has an effect on roadway safety. It has been demonstrated that the use of narrower lanes would lead to more crashes if other roadway characteristics remain unchanged (Harwood, et al., 2000). Heimbach et al. (1983) showed that crash rate increases as lane width decreases, but the relationship is not linear. Karlaftis and Golias (2002) quantitatively assessed the effects of various highway characteristics on crash rate using a crash database. They identified lane width as one of the most important factors affecting crash rate on two-lane roadways.

\subsubsection{Shoulder Width}

Shoulder width has also an impact on driving behavior. Yagar and Van (1983) found a small increase in driving speed on 2-lane rural roads if a hard shoulder was added. Stamatiadis, et al. (2009) suggested that wider shoulders give drivers a sense of security and much space to correct their driving errors. However, narrow lanes demand more mental concentration and could decrease the positive effects of wide shoulders on safety. In a study on safety relationships between geometric characteristics and crashes, Zegeer and Deacon (1987) concluded that crash rate decreased with increasing lane width and shoulder width. It was also observed that lane width had a greater impact on crash rate compare to shoulder-width. After examining crash rate on two-lane roads with three different shoulder widths (2, 4, and 8ft), Rinde (1977, in Dewar and Olson, 2001) found that narrower shoulders led drivers to steer away from shoulders and drove closer to the center of the road, which increases the likelihood of head-on collisions. Likewise, Kraus et al. (1993) found that narrow shoulders might create a dangerous condition where drivers don't have enough recovery area in case of lane deviation; therefore, this increases the likelihood of off-road collisions. After analyzing data from 600 two-lane rural road sections in Alabama, Michigan, and Washington, Miaou (1998) identified that 1ft increase in shoulder widths would decrease approximately $9 \%$ run-off-the-road crashes. In a similar study for rural two-lane roads in Washington and North Carolina, Council and Stewart (1999) found that increasing the shoulder width by $1 \mathrm{ft}$ leads to $5 \%$ to $10 \%$ reduction in crash rate at sections where daily traffic volume exceeds 5,000. Using three-year data from Minnesota and Washington for two-lane rural roads, Vogt and Bared (1998) suggested that a unit increase in shoulder width significantly reduces crash rate. However, it is noteworthy that wide shoulders don't mean safer situations to drivers. It has been shown that approximately $10 \%$ of fatal highway crashes are related to vehicles stopped on shoulders (Hauer, 2000). 
2

3

4

In the United States, rural two-lane roads sometimes lack physical objects that separate opposing traffic streams. It has been confirmed that the existence of median on highways have substantial influence on traffic flow operations and traffic safety. For example, Council and Stewart (1999) examined the safety differences between divided two-lane and undivided four-lane rural roadways. It was concluded that the existence of median barriers had positive effect on crash rate. Fitzpatrick et al. (2000) pointed out that the presence of medians results in higher speeds than where no median existed. The speed on streets without medians was about $38 \mathrm{mph}$, and the speed was $42 \mathrm{mph}$ with a raised median in urban areas. Tay and Churchill (2007) conducted a study related to drivers' perception of median barriers. Specifically, speed data were collected on freeways in the City of Calgary, Alberta with different types of longitudinal median barriers. They found that drivers increased speed since they perceived the barriers as a protective device. Another study conducted in Oregon suggested that crash rate would reduce if median barriers are used (Strathman, et al., 2001).

Most of these studies investigated the effects of weather and road geometry on average speed and crash rate in a macro scale. However, understanding of the underlying mechanisms, which lead to these changes in speed, flow, and crash rate, is essential to operate the transportation facilities under adverse road and weather conditions. This paper mainly focuses on incorporating the required parameters in a microscopic simulation model to capturing these mechanisms and model drivers' responses to reduced visibility from fog, different friction coefficients, different horizontal and vertical alignment, median types, and different lane and shoulder widths in realworld conditions.

\subsection{MODELING FRAMEWORK}

By reviewing the external factors of weather and road geometry, the objective is to investigate drivers' responses to reduced visibility, different road surface conditions, different horizontal and vertical curves, and different lane and shoulder widths in real-world conditions. This section introduces a model to capture the drivers' decision making process after processing the external information. Driving decisions are made based on drivers' current condition and the perceived information obtained from the external environment. Therefore, a reasonable and realistic drivers' decision representation should be dynamic rather than static. This study adopted the Hamdar et al. $(2008,2015)$ model to capture the dynamics in the decision making process. The decision making process in this model uses Kahneman and Tversky's Prospect Theory (1979). Based on this theory, the decision maker first assigns different weights to different alternatives considering corresponding gain and losses (framing or editing phase); and in then he/she evaluates these alternatives based on the prospect index (evaluation phase). The prospect index is calculated similar to the expected utility using subjective decision weights instead of expected probability of each outcome. This approach allows risk-taking maneuvers when drivers are uncertain of the leader's future behavior. Accordingly, crashes can be captured by this model endogenously. Note that despite providing a realistic representation of car-following behavior under normal conditions, most of other advanced car-following models introduce emergency breaking mechanisms to preclude high-risk maneuvers (e.g. maneuvers that can lead to a crash) in the simulation environment. Another advantage of the Prospect Theory based model is the 
inclusion of parameters that capture stochasticity and the distribution associated with the acceleration values rather than simply looking at a deterministic acceleration value produced through a given equation.

Driving in adverse weather condition as well as challenging roadway geometries involves stochasticity and high-risk maneuvers. In fact, in extreme driving conditions, drivers are more likely to make poor decisions due to the roadway condition, limited visibility, etc. Therefore, from the modeling perspective, the car-following framework should be able to model the occurrence of these high-risk maneuvers. Considering all these modeling requirements, Prospect Theory based car-following model is an excellent modeling framework for the purpose of this study.

Figure 1 illustrates the dynamic relationships inherent in the proposed Prospected Theory based acceleration model. For every decision interval, drivers choose their acceleration based on different value functions representing diverse driving environments. The final utility reflects a speed-acceleration value that the driver considers to be safe over the anticipation time period. The model calculates the state vector of the $n^{\text {th }}$ vehicle at each time instance $i$ :

$S_{n, i}=\left\lfloor x_{n, i}, v_{n, i}, a_{n, i}\right\rfloor$

Where $x_{n, i}$ is the position of the $n^{\text {th }}$ vehicle (the following vehicle) at time instance $i$; $v_{n, i}$ and $a_{n, i}$ represent the $n^{\text {th }}$ vehicle's velocity and acceleration at time instance $i$, respectively. The state vectors $s_{n, i}$ is then applied to calculate the acceleration $a_{n, i+1}$.

\subsection{Prospect Theory Model and Additional Parameters}

A set of model parameters were incorporated in the extended Prospect Theory based model to characterize the decision making circumstances. The extended value function adopted in this paper is given by:

\section{Place Fig. 1}

$U_{P T}\left(a_{n}\right)=\frac{\left(w^{-}+\left(1-w^{-}\right)\left(\tanh \left(\frac{a_{n}}{a_{0}}\right)+1\right)\right)}{\psi} \times \frac{\left(\frac{a_{n}}{a_{0}}\right)}{\left(1+\left(\frac{a_{n}}{a_{0}}\right)^{2}\right)^{\gamma}}$

Where:

$U_{P T}\left(a_{n}\right)=$ The value function,

$w^{-}=$Weighing factor for the prospect theory value,

$\gamma=$ Exponent of the prospect theory value mainly reflecting road impact,

$a_{0}=$ Acceleration normalizing factor,

$\psi=$ Amplitude factor for the prospect theory value mainly reflecting weather influence.

This extended value function was introduced based on the observations from the driving simulator experiments. In general, it is expected that in favorable weather conditions, unlike adverse weather conditions (e.g. foggy weather), drivers tend to avoid abrupt changes in 
acceleration and speed to enhance their comfort. Accordingly, this study defined the parameter $\psi$ to reflect this driver behavior. Lower $\psi$ value results in an increase in the sensitivity to acceleration/deceleration and results in less abrupt changes in acceleration and speed (for more details see Section 5.4 and Figure 8). Moreover, the parameter $\gamma$ is introduced to capture the effects of roadway geometry on drivers' acceleration choices. Drivers tend to predict the roadway geometry and adjust their acceleration and speed to enhance safety. Therefore, drivers put more effort on acceleration/speed choices while dealing with a challenging roadway geometry. Lower values of $\gamma$ increases the sensitivity to roadway geometry and results in more conservative acceleration choices by drivers (for more details see Section 5.4 and Figure 8). A detailed discussion on the effect of these parameters are presented in Section 5.4.

The drivers will gain $U_{\mathrm{PT}}$ by choosing $\mathrm{a}_{\mathrm{n}}$ as the acceleration unless they involve in a crash. Hamdar et al. $(2008,2015)$ used the crash seriousness term, $k(v, \Delta v)$, to determines the disutility resulting from the crash,

$U\left(a_{n}\right)=\left(1-p_{n . i}\right) U_{P T}\left(a_{n}\right)-p_{n, i} w_{c} k(v, \Delta v)$

where $p_{n, i}$ is the probability of being involved in a rear-end collision. $U_{P T}\left(a_{n}\right)$ is derived from equation 3.2 and $w_{c}$ is a crash weighting parameter which is lower for aggressive drivers. Capturing the stochastic nature of the acceleration choice, Hamdar et al. $(2008,2015)$ obtained the logistic functional form as follow,

$$
f\left(a_{n}\right)= \begin{cases}\frac{e^{\left(\beta_{P T} \cdot U\left(a_{n}\right)\right)}}{a_{\max }} & a_{\min } \leq a_{n} \leq a_{\max } \\ \int_{a_{\min }} e^{\left(\beta_{P T} \cdot U\left(a^{\prime}\right)\right)} & \\ 0 & \text { Otherwise }\end{cases}
$$

where $\beta_{P T}$ is the sensitivity of choice to the total utility. In ideal conditions, the follower can drive at his/her desired speed to follow the leader. Desired speed is the speed drivers would drive on a straight and level road section in clear day and without traffic disruptions. However, a driver's real travel speed is restricted by those aforementioned external factors as well as the leader's behavior. Accordingly, drivers may accelerate or decelerate until they obtain an acceptable utility corresponding to the driving environment; if the surrounding conditions change, the utility function is also subject to change. Therefore, drivers always evaluate to what extent they need to regulate their current speed to adapt to the new upcoming driving environment.

\subsection{EXPERIMENTAL SET-UP}

Once the hypotheses on the impact of different weather and roadway condition on acceleration behavior are defined within the Prospect Theory based modeling framework, a numerical study supporting such hypotheses is needed. Using a driving simulator is an alternative for on-road tests when researchers wish to use more controlled circumstances, or manipulate specific test conditions. Driving simulators are useful tools for the studies of driving behavior and traffic 
safety. By providing feedback in the form of visual, motion, and audio cues to drivers, a driving simulator can give drivers the impression that they are driving an actual vehicle in the real world. By simulating vehicle motion based on the driver operations, the vehicle kinematic data can in turn be used to extract trajectory data, which in turn can be used to analyze driving behavior. This section introduces the procedures related to the driving experiment set-up.

\subsection{3-D Driving Simulator}

The simulator software used in this study was originally developed for the National Highway Traffic Safety Administration in the 1980's. It is a product of Systems Technology, Inc. on lowcost techniques for creating laboratory test relevant to the psychomotor and cognitive activities of real world driving. The version currently in use of our studies is STISIM Drive Build 1.02.07. The vehicle dynamics program in use is VDANL Drive version 6.0.30 and it allows for userspecifiable, realistic steering and speed control characteristics.

The STISIM Driving simulator is the main apparatus applied in this study. Driving performances of many subject populations have been studied in driving simulators (Lee, et al., 2005, Shechtman, et al., 2007). A total of 36 students and staff from the George Washington University, 26 male and 10 female, with different driving experience participated in the experiments. Note that this sample mostly consists of younger drivers. Upon the participants' arrival in the laboratory, a questionnaire was completed by each participant, which includes several questions about their individual background and driving experience. In addition, each participant was briefed on the requirements of the driving test. They were instructed to follow their normal driving acceleration behavior. Since this paper focuses on acceleration behavior, the drivers were instructed to follow a "yellow cab" without performing any lane-changing.

The participants' average age was 24.8 years (std 4.02 years), ranging from 20 to 35 year. Every participant had a valid US driving license with 6 years of driving experience on average (std 4.50 years). None of the participants had previous experience with the driving simulator or reported any history of visual problems. Among 36 participants, 6 ( 1 female, 5 males) had road crashes in the past 5 years and one (male) refused to answer the corresponding "crash history" question. The 26 males and 10 females were randomly assigned to two or three of the 15 experimental scenarios (5.5 minutes each with around 3 minutes of pre-experiment driving and 1.5 minute of post-experiment driving: around 10 minutes of total driving using the simulator). Details about these experiments are presented in the next section. With this assignment, each experiment had at least 3 participants ( 1 female participant and 2 male participants).

\subsection{Driving Scenarios and Data Collection}

\subsubsection{Generic Environmental Settings}

The simulation scenarios in this study consisted of different weather conditions and road geometric configurations. In standard scenario, the test route was an $8000 \mathrm{ft}$ stretch of a four-lane roadway through a rural landscape. A series of metal median barriers with the dimensions of $10 \mathrm{ft}$ long, $1.5 \mathrm{ft}$ wide and $1.5 \mathrm{ft}$ high were displayed in the middle of the roadway. In the standard scenario, the lane width and the shoulder width of the roadway in both directions were $12 \mathrm{ft}$ and 
$6 \mathrm{ft}$, respectively. Speed limit signs of $65 \mathrm{mph}$, white dashed lines as the lane markings and white solid line at edge were posted throughout the scenario. The stripes of lane marking are 10ft long and were separated by $10 \mathrm{ft}$ interval. The line width of the edge lines and lane markings were all $0.33 \mathrm{ft}$. The cross-slopes for the travel lanes of both sides were set to slope down 1 percent from the roadway center to its edge. As for the cross-slope of shoulders on both sides, it was set to 2 percent grade sloping down from the center of the roadway to the roadway's outer edges. Just past the shoulders on both sides, there were 10ft wide fore-slopes that had 5 percent grade sloping downward. The weather condition for the standard scenario was set to a clear day with blue skies with no wind that may influence vehicle maneuverability. The simulator was programmed to simulate a rural environment. Table 1 presents the events used in use in the experiments.

The traffic condition consisted of multiple vehicles traveling on both directions of the road. Steady streams of oncoming vehicles were created throughout each simulation. There was also steady traffic traveling in the same direction as the driver in both the center lane and side lane. In addition, one lead "yellow cab" vehicle was programmed to travel on the side lane throughout the simulation of the standard scenario. In order to make the movement of the lead vehicle as generic as possible, the traffic data collected in the Federal Highway Administration's Next Generation Simulation project (FHWA, 2005) were adopted to define the speed profile of the lead vehicle in this study. There were three data sets collected from 4:00 PM to4:15 PM (data set 1), 5:00 PM to 5:15PM (data set 2) and 5:15PM to 5:30PM (data set 3) on $13^{\text {th }}$ of April, 2005. The NGSIM data were recorded at every $1 / 10$ second and when selecting the speed data from the NGSIM data pool, the authors always ensured that there were at least five vehicles in front of the lead vehicle and at least 5 vehicles behind the lead vehicle; this guarantees a "car-following" scenario. Finally, Vehicle ID 482, Vehicle ID 1014 from data set 1, vehicle ID 606 from data set 2, and Vehicle ID 100, Vehicle ID 306 from data set 3 were selected as the data samples in the studies. The sequentially combined speed-time relationships of these five vehicles are presented in Figure 2a. Due to the limitation of the STISIM Drive, the simulator only allows the speed of the lead vehicle change 15 times during one single simulation. Therefore, the leader's speed was linearly smoothed (the speed of a vehicle can only be changed linearly in the driving simulator) according to the selected NGSIM data. Figure $2 \mathrm{~b}$ demonstrates the resulting speed profile.

\section{Place Table 1}

\section{Place Figure 2}

\subsubsection{Test Variables}

It was observed that median existence (Council and Stewart, 1999) and median type (Tay and Churchill, 2007) affects drivers' behavior and accordingly affects traffic efficiency and safety. Two different median types: metal median barrier and concrete median barrier (Figures $3 \mathrm{a}$ and $3 c$ ) were used in the experiment. Undivided road was also tested in this study (Figure 3b).

The lane width of a roadway also greatly affects the safety and comfort of drivers. Although $12 \mathrm{ft}$ lane width is desirable on both rural and urban roadways, there are circumstances where much narrower lane widths are used. For instance, the use of $10 \mathrm{ft}$ lane is acceptable when the traffic volumes are low in some area. AASHTO Green Book (2001) notes that lane widths substantially 
less than $12 \mathrm{ft}$ are considered adequate for a wide range of volume, speed, and other conditions. Actually, $9 \mathrm{ft}, 10 \mathrm{ft}$, and $11 \mathrm{ft}$ lane widths are all in use depending on the road condition (e.g. traffic demand, topographical constraints, etc.) and construction cost. In the experiments, $9 \mathrm{ft}$ and $10 \mathrm{ft}$ lane widths were tested for a long straight section of four-lane roadway (Figures $3 \mathrm{c}$ and $3 \mathrm{~d}$ ). A standard lane width of $12 \mathrm{ft}$ will always be used in our simulation when testing other external factors (e.g. visibility distances, friction coefficients of roadway surface, horizontal curves, and vertical curves). Similarly, $0 \mathrm{ft}$ and $3 \mathrm{ft}$ shoulder widths were also tested in the experiment (Figures $3 \mathrm{e}$ and $3 \mathrm{f}$ ).

According to the literature, horizontal curve is one major location of traffic crashes and smaller curve radius results in higher crash rate (Choueiri and Lamm, 1987). The transverse stability (includes slippage and overturn) happens before the longitudinal stability on a curve based on the vehicle steering theory. The drivers' comfort is also a decision factor in calculating the curve radius. When designing the roadway layouts in mountainous area (Figure 3g), six different horizontal curves were adopted. Three smooth horizontal curves were also used in the case of rolling terrain scenario (Figure $3 h$ ).

\section{Place Figure 3}

\section{Place Table 2}

\section{Place Table 3}

A roadway horizontal curvature consists of tangents (straight sections of road), curves (sections of roadway with a constant curvature) and spirals. The roadway will remain straight until the start of the curve is reached, and then will bend to the direction specified. The values of radius and deflection angle of horizontal curves used in the experiments are shown in Table 2. The Vertical Curve event in this simulator was selected to examine the elevation impact on driving behavior. A combination of constant grade sections with a vertical curve was used to create uphill and downhill segments. Table 3 presents the vertical curves applied in mountainous and rolling terrain.

It was confirmed in the literature that reduced visibility conditions have huge impact on rear-end crash rate (see background section for more details). In order to see the weather influence on longitudinal driving behavior, this study utilized the driving simulator-based method where foggy condition was simulated. The trajectory data of the subject vehicle and the lead yellow cab vehicle were analyzed in order to determine how drivers react when driving in varying reduced visibility conditions. Constant fog density was considered throughout each driving test and was adjusted to present four different sight distances $(65.62 \mathrm{ft}, 164 \mathrm{ft}, 328 \mathrm{ft}$ and $656.2 \mathrm{ft}$ ) (Figure 4). Note that the different levels of fog were operationally defined as the mean distance at which drivers could detect an object on a straight road.

Road surface condition also affects driver behavior. Drivers often become more cautious and/or nervous when encountering unusual roadway surface conditions (e.g. wet or icy conditions). The Road Surface Attribute event in STISIM Drive was used to define different road surface conditions. In this driving experiment, two different road surface conditions were created to 
simulate wet and icy roadway surfaces. When driving on normal roadway surfaces, the vehicle tires had enough traction to respond to steering input. However, when the friction coefficient reduced to 0.2 (icy condition) and 0.4 (wet condition), drivers found that the vehicle was harder to control and less responsive.

Table 4 presents the summery of all 15 scenarios suggested in this section. Note that in all of the 14 scenarios (excluding the standard scenario), only one external factor was changed. The standard scenario consists of two-lane rural road marked with single white edge lines and separated by metal median barrier.

\section{Place Figure 4}

\subsection{NUMERICAL ANALYSIS}

In this section, the results of driving simulator experiments are presented and the impacts of the external factors on longitudinal driving behavior are discussed in detail. The effects of the weather-related and the roadway geometry related factors on the microscopic traffic performance measures (speed, spacing ...etc.) are discussed first. The discussion continues by introducing the method used to calibrate the extended Prospect Theory based model parameters. The calibration results are presented next followed by a limited simulation study.

\subsection{Exploratory Insight}

The average speed is calculated for each group in the 15 experiments. The average choice of time headway and the corresponding standard deviation is also calculated for each experiment. In addition, three deceleration instances are analyzed: deceleration of the leader from high speed to medium speed ( $63 \mathrm{ft} / \mathrm{s}$ to $30.5 \mathrm{ft} / \mathrm{s})$, from medium speed to relatively low speed ( $31 \mathrm{ft} / \mathrm{s}$ to $15 \mathrm{ft} / \mathrm{s})$, and from low speed to extremely low speed $(15.2 \mathrm{ft} / \mathrm{s}$ to $1.88 \mathrm{ft} / \mathrm{s})$. Note that three acceleration instances, in each experiment, are also selected to evaluate the drivers' response to the acceleration behavior of the leader.

\section{Place Table 4}

\subsubsection{Choice of speed and time headway}

Car-following performance under the 15 different scenarios are measured on a stretch of road during 5.5 minutes of experiments. Table 5 presents the corresponding statistics. Excluding the standard scenario (standard scenario was used to familiarize the drivers with the simulator), the results reveal that participants tend to choose lower speed when traveling on narrower lanes or narrow shoulders. Similarly, the average speed under wet $(23.94 \mathrm{ft} /)$ and icy $(23.94 \mathrm{ft} / \mathrm{s}) \mathrm{road}$ surface conditions are slightly lower than other conditions. The results show that fog density has little to no effect on the drivers' choice of speed (average speeds in four different foggy conditions were all about $24 \mathrm{ft} / \mathrm{s}$ ). However, the standard deviations of speed in foggy conditions were greater than standard condition, except for the third case $(\mathrm{VD}=328 \mathrm{ft})$. Note that drivers were advised to follow a yellow cab in a car-following scenario. The driving pattern of the 
yellow cab was identical in all scenarios. Therefore, drivers had to choose similar speed values to keep up with the driving pattern of the yellow cab. Low visibility, however, could introduce more uncertainties that lead to more fluctuations in driving speed (higher standard deviation) in a car-following scenario.

When looking at longitudinal driving behavior, safe time headway, considering the speed and deceleration capability, is a major factor to prevent rear-end crashes. Choice of time headway is also affected by different weather and roadway conditions. When traveling on the undivided roadway, the participants had the smallest time headway (4.71s).

Driver behavior in foggy conditions can vary based on the fog density. In low and very low visibilities, drivers tend to keep their distance from the leader; therefore, very high time headways were observed. As the visibility distance increases, drivers tend to consider the leader in their decision making process; therefore, a decrease in time headways was observed (compared to low and very low visibilities). Note that the average time headway when visibility is $656.2 \mathrm{ft}$ is less than most of other scenarios. This finding is consistent with the findings of previous studies: drivers keep short headways (to follow visible cues) under poor visibility conditions (Evans, 2004). Moreover, maximum time headway was found on the rolling terrain ( $10.14 \mathrm{~s}$ ); this observation suggests that following a leader on a stretch of rolling terrain requires more effort and drivers often "lose" the leader (which leads to higher average time headway).

\subsubsection{Reactions to deceleration}

The control of longitudinal speed involves continuous information processing, situation judgment, and decision making in response to potential hazards and critical changes in traffic circumstances. Drivers' expectations and predictions about the new actions of other road users (especially the leader) are essential for a timely reaction to potential hazards. Untimely detecting or reacting to the decelerations of the leader may result in a rear-end collision. The possibility of an imminent crash is often expressed as Time-to-Collision (TTC), which is defined as the ratio of the distance between the lead vehicle and the following vehicle and the speed difference between these two vehicles. Lower values of TTC indicate higher risk of a rear-end collision. Hayward (1972) identified 4 seconds as the critical TTC below which the crash in imminent. Brown et al. (2001) also suggested a TTC threshold of 3 seconds.

Moreover, in this study, the maximum deceleration that was chosen by the follower is adopted as an indicator of drivers' aggresiveness. Note that, in this study, the maximum deceleration applied by the leader is $16 \mathrm{ft} / \mathrm{s}^{2}$. Comparisons are made between the choices of maximum deceleration of the follower and the leader. Among all these tests (excluding the standard scenario), the maximum deceleration was found in undivided roads, dense fog, and rolling terrain (above $20 \mathrm{ft} / \mathrm{s}^{2}$ ). High deceleration rates indicate that drivers could not effectively adjust their behavior according to the leader and they had to reduce their speed in a very short time. In contrast, a much proper deceleration was applied by the follower in the cases of 9ft lane width, divided road with Jersey barriers, and icy surface.

Figure 5 shows the minimum TTC and maximum deceleration that drivers applied when the leader was decelerating. Minimum TTC is 2.93 s (below 3 seconds), which happened in the case 
of undivided Road. Furthermore, the second minimum TTC is $3.02 \mathrm{~s}$, which belongs to the case of dense fog condition where visibility distance is just 65.62ft (following the leader without clear cues may lead to the lower TTC values in poor visibility conditions).

\subsubsection{Reactions to Accelerations}

Drivers' maximum acceleration and minimum distance headway are adopted to investigate the risk associate with the acceleration maneuvers. A reasonable distance gap should be maintained to prevent any rear-end crash. In this study, the maximum acceleration applied by the leader is $5.5 \mathrm{ft} / \mathrm{s}^{2}$. Planned comparisons are made between the choices of maximum acceleration of the follower and the leader. The maximum acceleration in each scenario is presented in Figure 6. Among all the experiments, the maximum acceleration was observed in the undivided road scenario $\left(11.03 \mathrm{ft} / \mathrm{s}^{2}\right)$. This observation indicates that driving on undivided roads is challenging and drivers select high acceleration and deceleration rates (based on the findings of Section 5.1.2) to follow the leader. The maximum accelerations under icy road surface condition and under the condition where the lane is $10 \mathrm{ft}$ wide are relatively low $\left(4.23 \mathrm{ft} / \mathrm{s}^{2}\right.$ and $3.71 \mathrm{ft} / \mathrm{s}^{2}$ respectively). This indicates that drivers become more conservative facing challenging road conditions. Similarly, the average maximum acceleration on road without hard shoulders and on road with narrower shoulders ( $3 \mathrm{ft}$ wide) is lower than the leader's average acceleration.

\section{Place Table 5}

\section{Place Figure 5}

In four poor visibility conditions, the maximum accelerations are $5.23 \mathrm{ft} / \mathrm{s}^{2}(65.62 \mathrm{ft}$ visibility distance), $4.27 \mathrm{ft} / \mathrm{s}^{2}$ (164ft visibility distance), $4.58 \mathrm{ft} / \mathrm{s}^{2}$ (328ft visibility distance), and $5.7 \mathrm{ft} / \mathrm{s}^{2}$ (656.2ft visibility distance). The values suggest that drivers are less likely to use a high acceleration rates when the leader is increasing its speed, since drivers' ability to anticipate is impaired in the foggy weather.

The minimum distance headway is also presented in Figure 6. The smallest minimum distance headway occurs in "Mountainous" road scenario $(25.28 \mathrm{ft}$ ) while the largest minimum distance headway was observed in the "rolling terrain" scenario. These observations suggest that the distance headway increases as the roadway geometry becomes more challenging. However, observations suggest that in a very challenging roadway geometry, drivers tend to focus on the driving environment rather than the car-following behavior.

The average distance headway during these "yellow cab" acceleration instances are also calculated in order to evaluate drivers tendency to follow an accelerating lead vehicle. The minimum averaged distance headway was observed in "the undivided road" experiment $(67.69 \mathrm{ft})$. The second minimum average distance headway $(86.59 \mathrm{ft})$ was observed in the poor visibility condition. As mentioned previously, drivers tend to maintain shorter distance headways in poor visibility condition. The largest average distance headway was observed on the divided road with Jersey barriers.

\subsection{Model Calibration}


This study adopts a genetic algorithm based optimization method to calibrate the extended Prospect Theory based model parameters to deal with the nonlinear nature of the acceleration model and stochasticity in drivers' choice of acceleration. The sample data that are collected from the driving simulator to calibrate the acceleration model include the trajectories of both the leader and the follower. More details on the calibration process can be found in Qin (2012) and Qin and Hamdar (2013).

\section{Place Figure 6}

\subsubsection{Calibration Results}

76 driving experiments in total are carried out on the driving simulator during the entire study. However, only 66 driving dynamic data sets are adopted in the calibration work. Among the 10 excluded experiments, there were 3 overtaking behavior: one in the standard scenario and another two in the undivided road scenarios. Four road edge excursions occurred: two on $9 \mathrm{ft}$ wide traveling lane, one on $10 \mathrm{ft}$ traveling lane and one on the road with a narrower shoulder of $3 \mathrm{ft}$. In addition, three rear-end collisions happened in the cases of mountainous areas, rolling terrain and heavy foggy condition (65.62ft visibility distance). Out of 66 remaining data sets, only 44 sets were kept after calibration. These sets satisfy the maximum error threshold of $33 \%$ (Qin, 2012; Qin and Hamdar, 2013). The resulting calibrated nine parameters $\left(\psi, \gamma, w^{-}, w_{c}, \tau_{\max }\right.$, $\alpha, \beta, \tau_{\text {corr }}$ and $R T$ ) are analyzed by means of multivariate analysis of variance (MANOVA). Accordingly, to reach statistically significant conclusions using the remaining 44 sets, results obtained from the 15 different test scenarios are regrouped into three major groups:

1. Normal Conditions (NC) including the scenarios of standard scenario, Jersey barrier, undivided road and rolling terrain;

2. Moderate Conditions (MC - moderately challenging conditions) including the scenarios of $10 \mathrm{ft}$ lane width, $3 \mathrm{ft}$ shoulder width, wet road surface, $656.2 \mathrm{ft}$ visibility distance and $328 \mathrm{ft}$ visibility distance;

3. Extreme Conditions (EC - extremely challenging roadway conditions) including the scenarios of $65.62 \mathrm{ft}$ visibility distance, $164 \mathrm{ft}$ visibility distance, mountainous areas, icy road surface, $9 \mathrm{ft}$ lane and road without hard shoulders.

Table 6 shows the three different driving conditions, in which the sample numbers are 11, 14 and 19 respectively. Figure 7 shows two examples of acceleration behaviors under different driving conditions (moderate and extreme). This figure ( $7 \mathrm{a}$ and $7 \mathrm{~b}$ ) reveals that in moderate condition, drivers use anticipation to provide a comfortable driving experience and avoid extreme acceleration/deceleration values. Such extreme acceleration/deceleration rates are seen (even if not frequently) in extremely challenging conditions. This finding does not mean however that the acceleration distribution does not have a clear peak in extremely challenging conditions. As it can be seen in Figures 7c and 7d, the moderately challenging conditions provide a less elaborate peak and a "wider" distribution especially around the mean value. Actually, if looking at the "peak" value, the acceleration value during moderately challenging conditions is greater than the acceleration value in the extremely challenging conditions. However, this decrease in acceleration rates used should not be explained as an increase in safety in extremely challenging conditions. Table 7 presents the calibration results for all three cases of normal, moderate, and extreme driving conditions. 
Place Table 6

\section{Place Figure 7}

\subsection{MANOVA Test}

In this section, the multivariate analysis of variance (MANOVA) of all 9 parameters is presented. The MANOVA test is applied to explore how independent variables (IVs, the changes of external factors) influence the response of the dependent variables (DVs, the changes of the 9 parameters in each condition). The test results reveal the statistically important independent and dependent variables.

Since we are interested in understanding the similarities and differences between the three different groups, the following hypotheses are considered,

- Homogeneous variance and covariance matrix (note that the result of Box's Test ( $p=$ 0.163 ) for the covariance and Levene's Test for the variance indicate that these hypotheses cannot be rejected. For more detail see Qin and Hamdar, 2013),

- The dependent variables are normally distributed within groups.

The data structure of the MANOVA test is showed in the table 8 , some of the calculations involved in the MANOVA test are also listed as follows:

Level Mean

$$
\begin{gathered}
\bar{x}_{i}=\frac{1}{n} \sum_{j=1}^{9} x_{i j} \\
\bar{x}_{j}=\frac{1}{n} \sum_{i=1}^{3} x_{i j} \\
\bar{x}=\frac{\sum_{i=1}^{3} \sum_{j=1}^{9} x_{i j}}{\sum_{i=1}^{3} n_{i}}
\end{gathered}
$$

Grand Mean

$$
S S T=\sum_{i=1}^{3} \sum_{j=1}^{9}\left(x_{i j}-\bar{x}\right)^{2}
$$

Sum of Squares for Error

$$
S S T=\sum_{i=1}^{3} \sum_{j=1}^{9}\left(x_{i j}-\bar{x}_{i}\right)^{2}
$$

Sum of Squares for Factor A

$$
S S A=\sum_{i=1}^{3} n_{i}\left(x_{i}-\bar{x}\right)^{2}
$$

The statistics of Multivariate Tests are calculated using SPSS. Table 9 shows the results of the MANOVA test. The results reveal that the values of dependent variables significantly depend on which test scenario. In other words, there exists a statistically significant difference between the values of dependent variables under different conditions and external factors affecting the extended Prospect Theory based model parameters. Meanwhile, these tests further prove that the changes in the values of those dependent variables can be regarded as mainly caused by the 
control factors in the driving experiments and the influences from stochastic factors during the experiments can be excluded.

To determine how the dependent variables differ for each independent variable, Tukey's HSD post-hoc test is preformed. Table 10 shows the results of this test. Note that in this table NC, MC, and EC represent Normal Condition, Moderate Condition, and Extreme Condition, respectively. The major findings from the statistics presented in this table are as follows,

1. Mean $\Psi(\psi)$ are statistically significantly different between Extreme Conditions \& Moderate Conditions $(\mathrm{p}=0.80)$,

2. Mean Wc $\left(w^{-}\right)$are statistically significantly different between Normal Conditions \& Moderate Road Conditions ( $\mathrm{p}=0.098$ ), and Normal Conditions \& Extreme Conditions with $(\mathrm{p}=.005)$,

3. Mean $\tau_{\text {corr }}$ are statistically significantly different between Moderate Conditions \& Extreme Conditions $(\mathrm{p}=0.092)$.

\section{Place Table 7}

\subsection{Parametric Framing during Different Weather/Geometry Conditions}

Before presenting the experimental design and the corresponding numerical results, different hypotheses may be suggested within the modeling framework presented earlier. Such hypotheses are related to the possible impact of the challenges faced during inclement weather conditions and non-favorable roadway characteristics on some of the models' parameters defined and calibrated in the previous sections.

In favorable weather conditions, drivers use smoother acceleration rates (less extreme with less elaborate peak) to reach a desired speed (see Figure 7). In contrast, in unfavorable weather conditions (e.g., poor visibility condition and slippery road surfaces), drivers sometimes resort to abrupt and wider acceleration/deceleration choices in response to the challenging surrounding environment. Accordingly, the parameter $\psi$ is introduced in Equation 3.2 to characterize the impact of weather on drivers' perceptions [of the driving environment. For illustration reasons, Figures 8a shows three value functions representing three different weather conditions utilizing different $\psi$ values (called amplitude term). This figure reveals lower sensitivity to the acceleration/deceleration values at higher values of $\psi$ (which can be interpreted as wider acceleration choices). Therefore, higher values of this parameter are expected for more challenging roadway geometries, which is confirmed by the statistically significant calibration results (compare the parameter values for moderate and extreme conditions in Table 7). Figure 8 e reveals the models' capability of capturing drivers' wider acceleration/deceleration choices at higher values of $\psi$.

Drivers predict the road geometrical configuration and regulate the speed and acceleration based on their subjective expectation about the geometric features of the upcoming road sections. When traveling on a road with a challenging geometry (e.g. a road section where a horizontal or vertical curve exists, or when the travel lane or the hard shoulder is narrower than the normal width), drivers need to invest more efforts to deal with the changes in geometry. Therefore, they 
are more likely to avoid high acceleration/deceleration rates and their expectations in gains may increase. Accordingly, the parameter $\gamma$ is introduced in Equation 3.2 to capture the effects of roadway geometry on drivers' acceleration choices. Figure $8 \mathrm{~b}$ shows three value functions representing three different roadway geometries utilizing different $\gamma$ values (called frequency term). This figure reveals lower sensitivity to the acceleration/deceleration values at higher values of $\gamma$ (which can be interpreted as wider acceleration choices). Therefore, lower values of this parameter is expected for more challenging roadway geometries, which is confirmed by the calibration results (see Table 7). Figure 8f reveals the models' capability of capturing drivers' narrower acceleration/deceleration choices at lower values of $\gamma$.

\section{Place Table 8}

\section{Place Table 9}

\section{Place Table 10}

Note that since drivers can anticipate the changes in roadway geometry and adjust their driving behavior in advance accordingly, the effects of roadway geometry on driver behavior is more limited compare to challenging weather conditions (in which drivers' anticipation ability is very limited due to, for instance, the lack of visibility). This observation is also reflected in the calibration results where calibrated $\gamma$ values are not statistically different between normal, moderate, and extreme weather conditions, whereas calibrated $\psi$ values are statistically different (see Table 10) between extreme and moderate conditions. This observation is in agreement with observations of Ibrahim and Hall (1994), Broughton et al. (2007), McLean (1981), and Heimbach et al. (1983).

Note that the $\psi$ parameter in the normal conditions (NC) is not statistically different from $\psi$ parameter in the moderately challenging conditions (MC). Accordingly, the authors may hypothesize that some level of weather related challenges may bring enough alert to smoothen traffic (less elaborate peak with no extreme accelerations/decelerations) compared to the normal conditions (with a self-confidence expressed by the drivers in normal conditions that may lead to further disruption and less safe conditions). However, when the challenge is increased, the peak of the distribution become more elaborate while extreme acceleration values are used (seen in the change in the values of $\psi$ ) leading to less safe conditions (even if lower acceleration rates on average are used). Even though such hypothesis is feasible, some caution is needed before fully supporting it. For such purpose, additional data may need to be collected.

\section{Place Figure 8}

\subsection{Model Performance}

In this section, driver behavior under different roadway and weather conditions (i.e. normal, moderate, and extreme conditions) is investigated through a set of simulations. A hypothetical one-lane highway with an on-ramp (to produce disturbance in driving environment) is selected for conducting simulations. The highway inflow rate is started from zero and increased until a flow drop is observed in the merging section. After this point, the inflow rate is kept at flow drop point until the end of the simulation. The ramp, however, has a constant inflow rate of $90 \mathrm{veh} / \mathrm{hr}$. 
The maximum speed during the simulation is set based on the observed loop detector data in the east-bound direction of I-290 near Chicago, IL in different roadway and weather conditions. Specifically, the average speed is calculated during morning peak hours (7AM to 10AM) for a day with heavy snow (representing an extreme condition), a day with low visibility (representing a moderate condition), and a clear day (representing a normal condition). Based on these observations, the maximum speed for the extreme conditions is set to $14 \mathrm{~m} / \mathrm{s}$, while the average speeds for the moderate and normal conditions are set to $18 \mathrm{~m} / \mathrm{s}$ and $21 \mathrm{~m} / \mathrm{s}$, respectively. Note that through comparison of the fundamental diagrams for different weather conditions, the performance of the microscopic model can be evaluated.

Figure 9 presents the simulation results for the first set of simulations. It is clear from this figure that scatter in fundamental diagram increases as the roadway and weather conditions shift from normal to extreme. Interestingly enough, the breakdown flow in all three roadway and weather conditions is around $1800 \mathrm{veh} / \mathrm{hr}$. However, despite similar breakdown flows, the breakdown densities vary across different roadway and weather conditions. The highest breakdown density is observed during the extreme condition and the lowest breakdown density is observed during the normal condition. The difference in breakdown densities is mainly due to the difference in maximum speeds and different slopes in the uncongested part of fundamental diagrams (compare $14 \mathrm{~m} / \mathrm{s}$ for the extreme condition with $21 \mathrm{~m} / \mathrm{s}$ for the normal condition).

Note that the presented results from both sets of simulations are in agreement with the real-world observations where disturbances in driving condition have less influence on driving behavior in normal roadway and weather conditions compare to extreme weather conditions. Moreover, based on the calibrated parameter values, it is noticed that the parameter $\Psi$ will increase when the weather conditions get worse and the parameter $\gamma$ will decrease when the road conditions get worse. Through the series of driving experiment conducted, and the subsequent parameter calibration, the hypotheses proposed in the Prospect Theory based model formulation part were found to be valid. Therefore, it can be concluded that the extended Prospect Theory based acceleration model's cognitive architecture are capable of jointly capturing the impact of two main types of external driving factors: the weather-related factors (visibility distances and road surface frictions), and the road-related factors (driving on undivided/divided road, lane width, shoulder width, horizontal and vertical curvature).

\subsection{CONCLUSIONS AND FUTURE RESEARCH NEEDS}

This study characterizes the longitudinal driving behavior under different road-geometry and weather conditions, as two factors that significantly affect congestion and safety in transportation systems. A prospect theory based car-following model of Hamdar et al. (2008) is extended to capture the behavioral dynamics resulting from these external factors. In order to test the proposed expanded model, 15 driving experiments are designed and carried out using the STISIM Drive simulator software. Throughout the test, 66 effective results are collected. The 66 car-following experiments conducted by 36 drivers are then used to calibrate the model using a Genetic Algorithm. Based on the calibration results, the model performance and the features of longitudinal driving behavior are discussed. 
The outcomes of the driving experiments are in accordance with the real-world observations. It is found that the overall drivers' average speed, time headway, time to collision, and distance headway are affected by both the roadway-related factors (lane width, shoulder width, median existence, median type, horizontal curves and vertical curves) and weather related factors (foggy weather and icy and wet road surface conditions). It has been confirmed that undivided road causes drivers to adopt an aggressive driving strategy (less safety margins - like time headway, large acceleration or deceleration are observed). Conversely, traveling on the divided road, drivers adopt less aggressive behavior. The narrower lanes are also found to be one of the influential factors that impact drivers driving style when following a leader. The most extreme case of $9 \mathrm{ft}$ traveling lane increases the distance with the leader compared to the normal case. Drivers driving on a road without hard shoulders are less likely to follow the leader at a dangerously close distance. Inadequate visibility distance is also found to influence driving behavior. Low visibility cause drivers to increase their distance with the leader, while in higher visibility drivers tend to follow the leader more closely. It is evident that driving on slippery road surfaces are much challenging and drivers become much vigilant. No apparent defensive or aggressive driving styles are observed when driving in mountainous areas (horizontal curves and vertical curves) and rolling terrains (vertical curves).

From the modeling perspective, Prospect Theory based acceleration model's cognitive architecture distinguishes two main types of information corresponding to different value functions: the weather-related information (visibility distances and road surface frictions), and the road-related information (driving on undivided/divided road, lane width, shoulder width, horizontal and vertical curvature). It is observed that parameters $\psi$, reflecting external weather impact, increases as weather condition gets worse. On the other hand, $\gamma$, reflecting external road impact, decreases when road condition gets worse. $W_{c}\left(w_{c}\right)$, which represents differences in drivers' safety attitude or crash sensitivity with respect to the leader's speed estimations and acceleration selections, is found to follow a decreasing pattern as the external driving environment gets challenging. This finding indicates that drivers become more aggressive in dealing with challenging roadway and weather conditions. Psychologically, drivers tend to underestimates the losses caused by a rear-end collision under extreme conditions and overestimate the crash losses when traveling under normal conditions. Finally, the simulation of a real-world segment indicated the models capability of simulating driver behavior under different roadway and weather conditions.

Note that extending the findings of this study to multilane highways with higher congestion level while accounting for socio-demographic characteristics of drivers in their decision-making constitute a future research direction to be adopted by the authors.

\section{Place Figure 9}

\subsection{ACKNOWLEDGEMENTS}

This material is based upon work supported by the National Science Foundation under Grant No. 0927138. Any opinions, findings, and conclusions or recommendations expressed in this material 
are those of the author(s) and do not necessarily reflect the views of the National Science Foundation.

\section{REFERENCES}

American Association of State Highway and Transportation Officials (AASHTO). (2001). A Policy on Geometric Design of Highways and Streets, Fourth Edition. Washington, D.C. Andueza, P. J. (2000). Mathematical Models of Vehicular Speed on Mountain Roads. Transportation Research Record 1701, Transportation Research Board, Washington, D.C. Barker, J., S. Farmer and M. Taylor. (1999). The Development of Accident-remedial Intervention Levels for Rural Roads. Report 425, Transport Research Laboratory Crowthorne House, Nine Mile Ride, Wokingham, Berk RG40 3GA

Bonneson, J., M. Pratt, J. Miles, and P. Carlson. (2007). Development of Guidelines for Establishing Effective Curve Advisory Speeds. Federal Highway Administration (FHWA), Report 0-5439-1.

Brackstone, M., B. Waterson and M. McDonald. (2009). Determinants of Following Headway in Congested Traffic. Transportation Research Part F: Traffic Psychology and Behavior, Vol. 12, pp. 131-142

Broughton, K., F. Switzer and D. Scott. ( 2007). Car-Following Decisions Under Three Visibility Conditions and Two Speeds Tested with a Driving Simulator. Accident Analysis and Prevention, Vol. 39, pp. 106.

Cambridge Systematics. (2011). Crashes vs. Congestion-What's the Cost to Society? http://newsroom.aaa.com/wpcontent/uploads/2011/11/2011_AAA_CrashvCongUpd.pdf

Brown, T. L., J. L. Lee and D. McGehee. (2001). Human Performance Models and Rear-End Collision Avoidance Algorithms. Human Factors, Vol. 43, No3 Fall 2001, pp. 462-482

Chen, S., T. Sheridan, S. Ahn, M. Mathew, M. Kambourides, H. Kusunoki and N. Komoda. (1995). Car-following Behavior: Effect of Environment. Proceedings of the 1995 Annual Meeting of ITS America, Washington, D.C., pp. 993-999

Choueiri, E. M. and R. Lamm. (1987). Rural Roads Speed Inconsistencies Design Methods: Part I, Operating Speeds and Accident Rates on Two-Lane Rural Highway Curved Sections. Department of Civil and Environmental Engineering, Clarkson University, NY

Cirillo, J.A. and F. M. Council. (1986). Highway Safety: Twenty Years Later. Transportation Research Circular, 1068, pp. 90-95

Council, F. M. and J. R. Stewart (1999). Safety Effects of the Conversion of Rural Two-Lane to Four-lane Roadways Based on Cross-Sectional Models. Transportation Research Board Annual Meeting, Washington, D.C.

De Waard, D., M. Jessurun, F. J. Steyvers, P. T. Raggatt and K. A. Brookhuis. (1995). Effect of Road Layout and Road Environment on Driving Performance, Drivers' Physiology and Road Appreciation. Ergonomics 38 (7), pp.1395-1407

Dewar, R. E., and P. L. Olson. (2001). Human Factors in Traffic Safety. Lawyers \& Judges Publishing Company

Evans, L. (2004). Traffic Safety. Science Serving Society, Bloomfield Hills, MI

FHWA. (2005). NGSIM Task E.1-1: Core Algorithms Assessment, Final Report, Cambridge Systematic, Inc., Massachusetts. 
Fitzpatrick, K., P. J. Carlson, M. D. Wooldridge and M. A. Brewer. (2000). Design Factors that Affect Driver Speed on Suburban Arterials. Project Summary Report 1769-S. Austin, Texas: Texas Transportation Institute

Glennon, J. (1987). Effect of Alignment on Highway Safety, Relationship between Safety and Key Highway Features. SAR 6. Transportation Research Board, Washington, D.C., PP. 48-63

Hamdar, S. H., M. Treiber, H. S. Mahmassani and A. Kesting. (2008). Modeling driver behavior as sequential Risk-Taking task, Transportation Research Record: Journal of the Transportation Research Board, No. 2088, pp. 208-217

Hamdar, S. H., H. S. Mahmassani and M. Treiber. (2015). From Behavioral Psychology to Acceleration Modeling: Calibration, Validation, and Exploration of Drivers' Cognitive and Safety Parameters in a Risk-Taking Environment. Transportation Research Part B: Methodological, Vol. 78, pp. 32-53.

Harwood, D. W., F. M. Council, E. Hauer, W. E. Hughes and A. Vogt. (2000). Prediction of the Expected Safety Performance of Rural Two-Lane Highways, Report FHWA-RD-99-207, Federal Highway Administration

Harwood, D.W. (1990). Effective Utilization of Street Width on Urban Arterials, National Cooperative Highway Research Program Report 330, Transportation Research Board

Hawkins, R.K. (1988). Motorway traffic behaviour in reduced visibility conditions. In A. G. Gale, Proceedings of the Second International Conference in Vision in Vehicles, Amsterdam, pp. 9-18

Hayward, J.C. (1972). Near miss determination through use of a scale of danger. Highway Research Record, 384, pp.24-34

Heimbach, C.L., P.A. Cribbins and M.S. Chang. (1983). Some partial consequences of reduced traffic lane widths on urban arterials. Transportation research record 923, pp.69-72 Heimbach, C.L., P.A. Cribbins and M.S. Chang. (1983). Some partial consequences of reduced traffic lane widths on urban arterials. Transportation research record 923, pp.69-72.

Hogema, J.H. and W.H. Janssen. (1996). Effects of intelligent cruise control on driving behavior. TNO Human Factors. Soesterberg, The Netherlands, Report TM-1996-C-12

Hoogendoorn, R.G., S.P. Hoogendoorn, K.A. Brookhuis and W. Daamen. (2010). Simple and multi-anticipative car-following models: Performance and parameter value effects in case of fog. Proceedings TFTC Summer Meeting, pp. 2-16

Hughes, W. and G. Amis. (1996). Accidents on Rural Roads: Single Carriageway 'A' Class Roads, AA Foundation for Road Safety Research, Basingstoke, Hants

Ibrahim, A.T., and F.L. Hall. (1994). Effect of Adverse Weather Conditions on Speed-FlowOccupancy Relationships, Transportation Research Record 1457, Transportation Research Board, Washington, D.C

Janssen, W.H., S.N. de Ridder, R.F.T. Brouwer and the RISER Consortium, (2006). Roadside Infrastructure for Safer European Roads: D02-Summary of Driver Behaviour and Driver Interactions with Roadside Infrastructure, Project RISER, European Community under the Competitive and Sustainable Growth Program

Johnston, I.R. (1982). Modifying Driver Behavior on Rural Road Curves- A Review of Recent Research. Proceedings of the Eleventh Australian Road Research Board Conference, University of Melbourne, Australia 
Kahneman, D. and A. Tversky. (1979). Prospect Theory: an Analysis of Decision under Risk, Econometrica, Vol. 47, No. 2, pp.263-291

Karlaftis, M.G. and I. Golias (2002). Effects of road geometry and traffic volumes on rural roadway accident rates. Accident Analysis and Prevention 34, pp.357-365

Karlaftis, M.G. and I. Golias. (2002). Effects of road geometry and traffic volumes on rural roadway accident rates. Accident Analysis and Prevention 34, pp.357-365

Kesting, A. and M. Treiber. (2008). Calibrating Car-Following Models Using Trajectory Data: Methodological Study

Knuiman, M.W., F.M. Council and D.W. Reinfurt. (1993). Association of median width and highway accident rates. Transportation Research Record, issue no. 1401, pp. 70-82.

Kraus, J.F., C.L. Anderson, S. Arzemanian, M. Salatka, P. Hemyari and G. Sun (1993). Epidemiological aspects of fatal and severe injury urban freeway crashes. Accident Analysis and Prevention 25 (3), pp.229-239

Krebs, H.G. and J.H. Kloeckner. (1977). Investigation of the Effects of Highway and Traffic Conditions outside Built-Up Areas on Accident Rates. Forschung Strassenbau und Strassenverkehrstechnik, pp.223.

Lefeve, B.A. (1953). Speed Characteristics on Vertical Curves. Highway Research Board Proceedings, 32, pp. 395-413

Leisch, J.E. (1971). Alignment in Traffic Control and Roadway Elements: Their Relationship to Highway Safety. Highway Users Federation for Safety and Mobility, Washington, DC. Wardrop, J.G. Some Theoretical Aspects of Road Traffic Research. In Proceedings Institute of Civil Engineers. Road Engineering Division Meeting, London, Great Britain, January 1952, pp. 325-362

Liang, W.L., M. Kyte, F. Kitchener and P. Shannon. (1998). The Effect of Environmental Factors on Driver Speed: A Case Study, Transportation Research Record 1635, Transportation Research Board, National Research Council, Washington, D.C., pp. 155-161 Martens, M., S. Comte and N. Kaptein. (1997). The effects of road design on speed behaviour: a literature review. Deliverable D1 (Report 2.3.1), MASTER

McLean, J. (1981). Driver Speed Behavior and Rural Road Alignment Design. Traffic Engineering and Control, 22(4), pp. 208-211

Miaou, S.P. (1998). Vertical Grade Analysis Summary, unpublished Technical Memorandum to FHWA, Washington, D.C.

Mullins, B.F.K and J.F. Keese. (1961). Freeway traffic accident analysis and safety study, Highway Research Board Bulletin 2915, Highway Research Board

Najm, W.G., S. Basav, J.D. Smith and B.N. Campbell. (2003). Analysis of light vehicle crashes and pre-crash scenarios based on the 2000 General Estimates System, NHTSA Technical report DOT HS 809573

National Highway Traffic Safety Administration, National Center for Statistics and Analysis. ( 2012 ) . Early Estimate of Motor Vehicle Traffic Fatalities in 2011, Report No. DOT HS 811 604, http://www-nrd.nhtsa.dot.gov/Pubs/811604.pdf

Perrin, J. and P. Martin. (2002). Modifying Signal Timing during Inclement Weather, University of Utah Traffic Lab, presented at the 2002 Institute of Transportation Engineers Annual Meeting

Polus, A., M. Pollatschek and H. Farah. (2005). Impact of infrastructure characteristics on 
road crashes on two-lane highways. Traffic Injury Prevention 6 (3), pp.240-247 Qin, L. (2012). Weather and Road Geometry in Microscopic Acceleration Modeling: Formulation and Numerical Analysis. M. S. Thesis, The George Washington University

Qin, L. and S.H. Hamdar. (2013). Weather and Road Geometry impact on Acceleration Behavior: Experimental Set-Up and Data Collection Using a Driving Simulator, Traffic and Granular Flow'13, Springer, ISBN 978-3-319-10628-1.

Rockwell, T. R (1972). Skills, Judgment, and Information Acquisition in Driving, Human Factors in Highway Traffic Safety Research, Wiley, New York

Shankar, V., F. Mannering and W. Barfield. (1995). Effect of Roadway Geometrics and Environmental Factors on Rural Freeway Accident Frequencies. Accident Analysis and Prevention 27, pp. 371-389

Shankar, V., F. Mannering and W. Barfield. (1996). Statistical Analysis of Accident Severity on Rural Freeways, Accident Analysis and Prevention 28, pp. 391- 401

Stamatiadis, N., J. Pigman and J. Sacksteder, W. Ruff and D. Lord. (2009). Impact of shoulder width and median width on safety. National Cooperative Highway Research Program (NCHRP), Report No. 633. Transportation Research Board

Stamatiadis, N., K. Bailey, T. Grossardt, J. Ripy and A. Strombotne. (2007). Use of contextsensitive methods to influence operating speeds. Transportation Research Record: Journal of the Transportation Research Board No. 2025. Transportation Research Board of the National Academies, Washington, DC, pp. 90-97

Strathman, J., K. Duecker, J. Zang, and T. Williams. (2001). Analysis of Design Attributes and Crashes on Oregon Highway System, Report FHWA-OR-RD-02-01. FHWA, Washington, DC

Summala, H. (1996). Accident risk and driver behavior. Safety Science 22 (1-3), pp.103-117

Tanaka, M., P. Ranjikar and T. Nakatsuji. (2010). Comparison of Driving Behavior and Safety in Car-following Platoons under Icy and Dry Surface Conditions, Transportation Research Board 89th Annual Meeting, Compendium of Papers DVD, 10-0504, Monograph Accession, 01147878

Talebpour, A., H. Mahmassani, and S. Hamdar. (2011). Multiregime Sequential Risk-Taking Model of Car-Following Behavior. Transportation Research Record: Journal of the Transportation Research Board, 2260(-1): p. 60-66.

Tay, R., Churchill, A. (2007). Effect of different median barriers on traffic speed. Canadian Journal of Transportation 1 (1)

Van Der Hulst, M., T. Rothengatter and T. Meijman. (1998). Strategic adaptations to lack of preview in driving. Transportation Research Part F 1 (1), pp.59-75

Vey, A.H. and M.G. Ferreri. (1968). The Effect of Lane Width on Traffic Operation. Traffic Engineering, 38(8), pp. 22-27

Vogt, A., and J. G. Bared. (1998). Accident Models for Two-Lane Rural Roads: Segments and Intersections. Report No. FHWA-RD-98-133, Federal Highway Administration, Washington, D.C.

Wallman, C. G., P. Wretling and G. Oeberg. (1997). Effects of Winter Road MaintenanceState of the Art. Swedish Road and Traffic Research Institute (VTI) Sartryck, Report No. 423 Walmsley, D. and I. Summersgill. (1998). The Relationship Between Road Layout and Accidents on Modern Rural Trunk Roads, report 334, Transport Research Laboratory 
Crowthorne House

Winsum, W. V. (1999). The human element in car following models. Transportation Research Part F 2, pp.207-211.

World Health Organization. (2004). World report on road traffic injury prevention: summary.http://www.who.int/violence injury prevention/publications/road traffic/world re port/summary_en_rev.pdf

Wu, Y. and G. Pan. (2009). A Smart Car Control Model for Brake Comfortable Based on Car Following, IEEE Transcations on Intelligent Transportation Systems, Vol. 10, No.1, pp. 4246

Yagar, S. and M. A. Van. (1983). Geometric and Environmental Effects on Speeds on 2-lane Rural Roads. Transportation Research Record, Vol. 17A, 4, pp. 315

Yagar, S. and Van A. M. (1983). Geometric and Environmental Effects on Speeds on 2-lane Rural Roads. Transportation Research Record, Vol. 17A, 4, pp. 315

Yang, H. H. and H. Peng. (2010). Vehicle System Dynamics, Vol. 48, Supplement 1, pp. 525-535

Zegeer, C., R. Stewart, D. Reinfurt, F.M. Council, T. Neuman, E. Hamilton, T. Miller and W. Hunter. (1990). Cost Effective Geometric Improvements For Safety Upgrading of Horizontal Curves. Publication No. FHWA-RD-90-021, University of North Carolina, Highway Safety Research Center, Chapel Hill, NC

Zegeer, C.V. and Deacon, J.A. (1987). Effect of lane width, shoulder width and shoulder type on highway safety, In State of the Art Report Number 6: Relationship Between Safety and Key Highway Features, Transportation Research Board, Washington, D.C., pp. 1-21

Zwahlen, H.T., T. Hagiwara and T. Schnell. (1995). Visibility of New Yellow Center Stripes as a Function of Obliteration, Proceeding of 74th Annual Meeting of the Transportation Research Board, Washington D.C. 


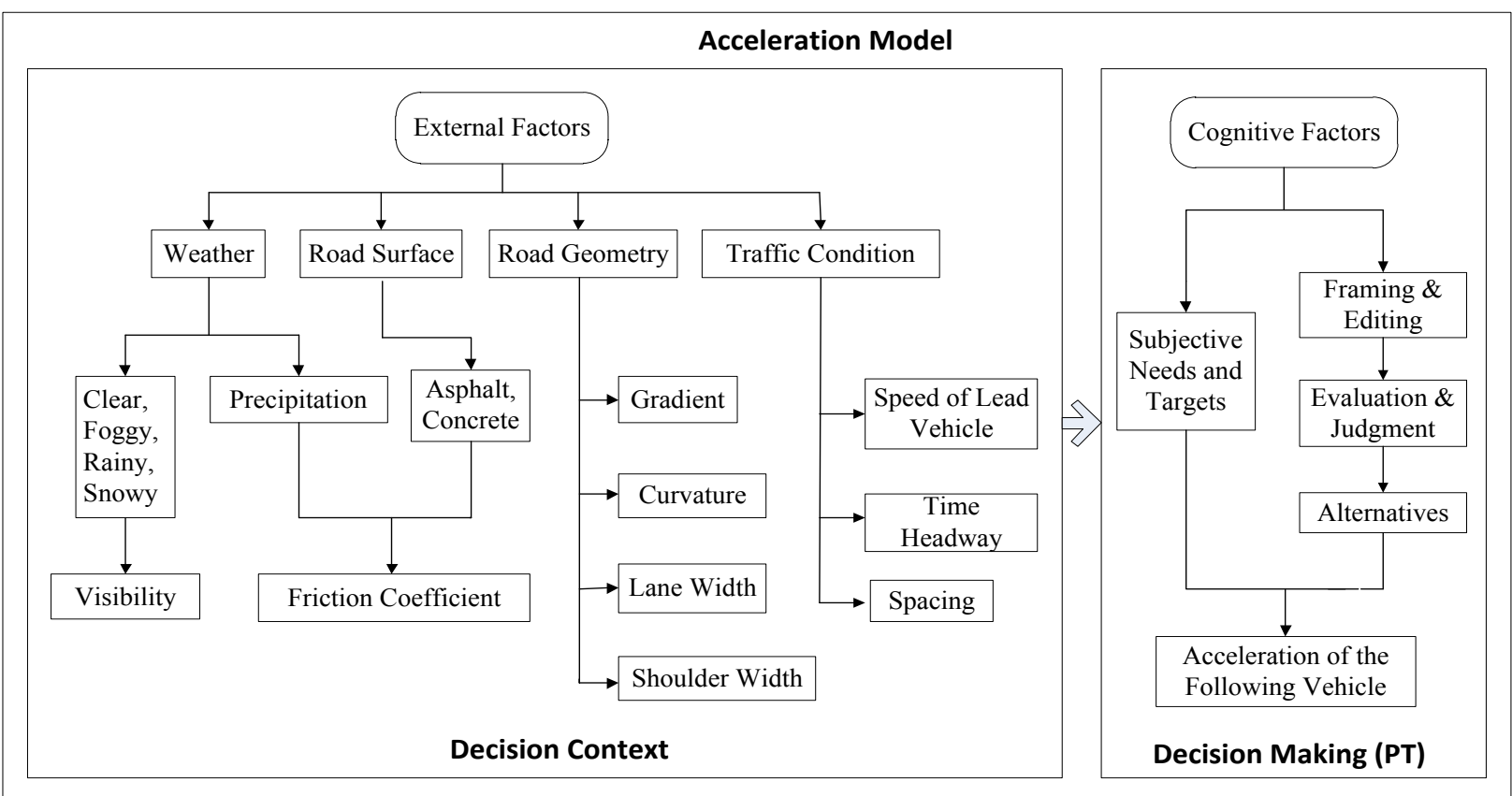

Figure 1 Schematic of Prospect Theory Based Acceleration Model. 


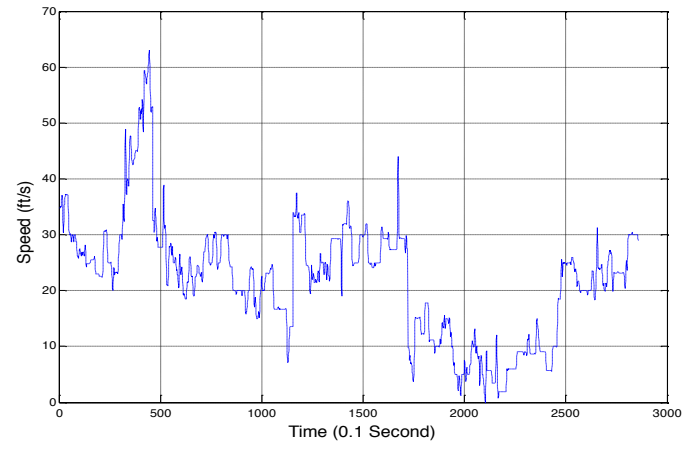

(a)

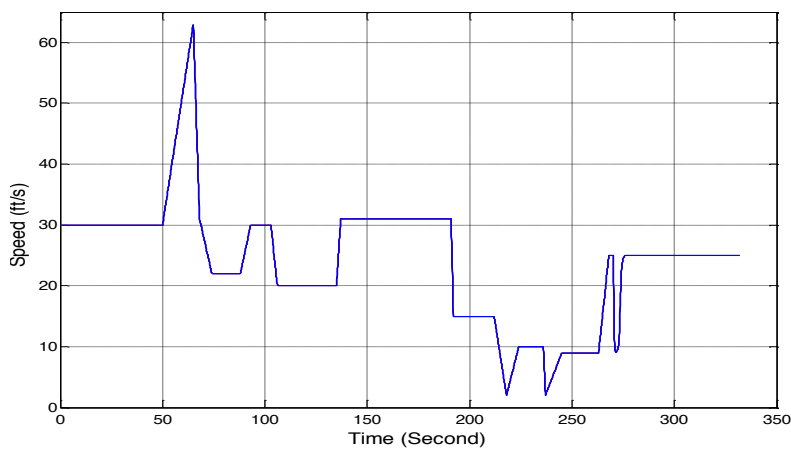

(b)

Figure 2 (a) Raw Data of Speed Profile Selected for the Lead Vehicle Based on NGSIM Data (FHWA, 2005), (b) Speed Profile of the Lead Vehicle Defined in the Driving Simulator. 


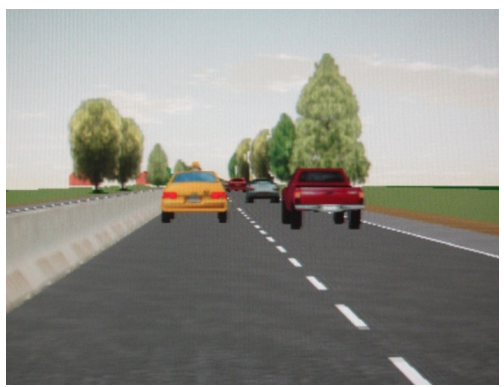

(a)

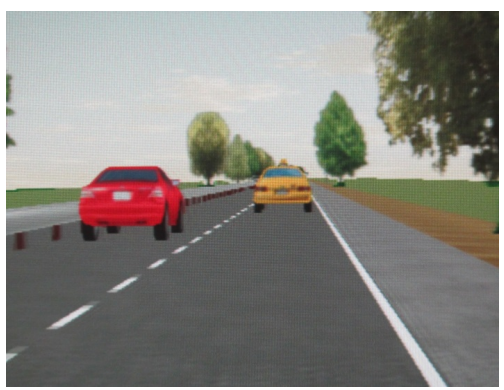

(d)

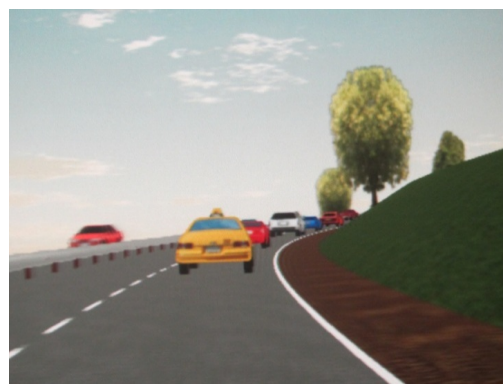

(g)

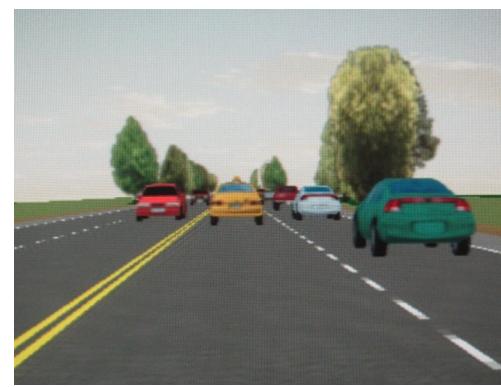

(b)

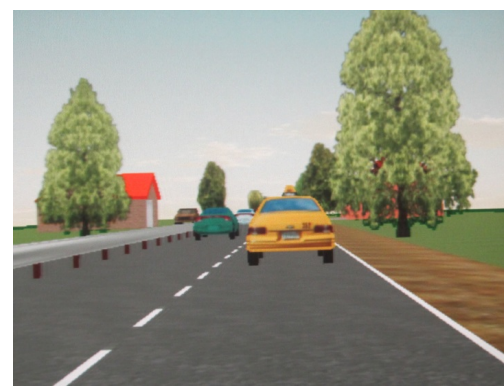

(e)

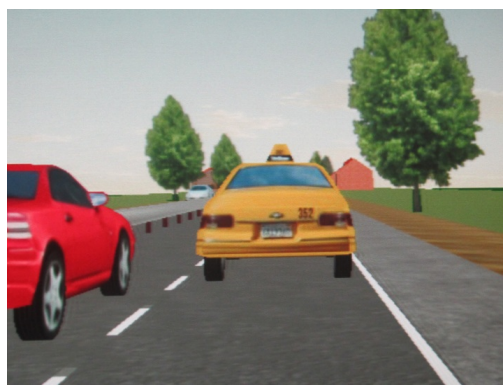

(c)

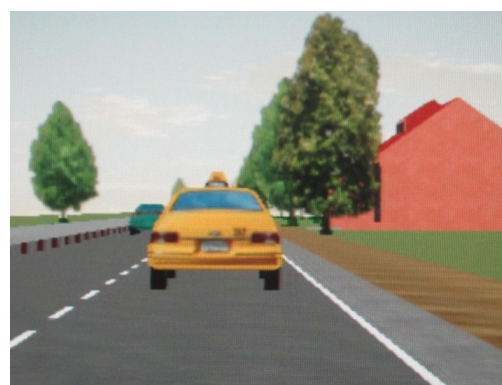

(f)

Figure 3 (a) Jersey Barrier, (b) Undivided Road, (c) 9ft Wide Lane with Metal Barrier, (d) 10ft Wide Lane Rolling Terrain.

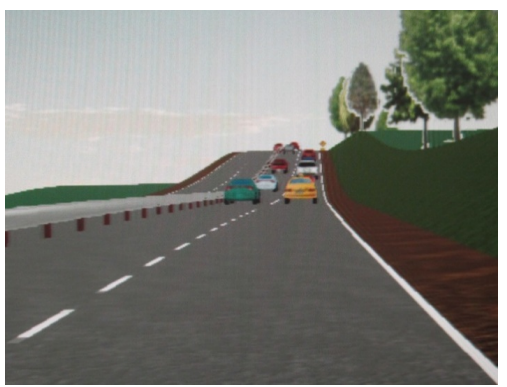

(h)

\section{2 with Metal Barrier, (e) No Hard Shoulders, (f) $3 \mathrm{ft}$ Wide Hard Shoulder, (g) Mountainous Terrain, and (f)} 3 


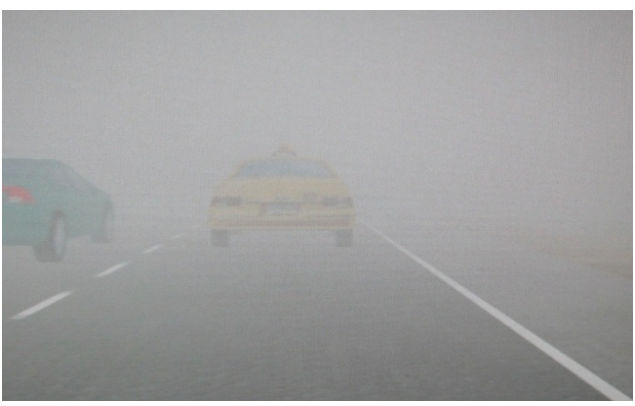

(a)

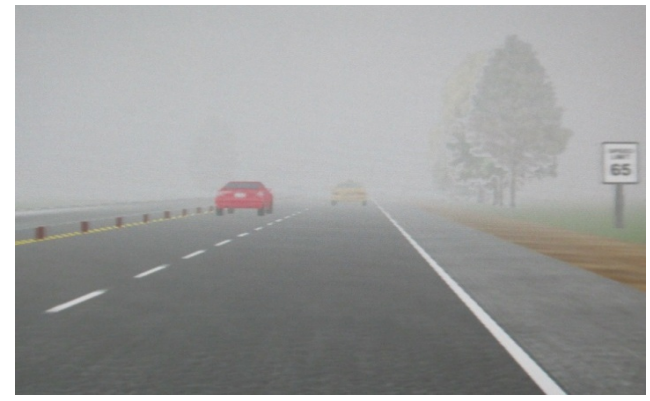

(c)

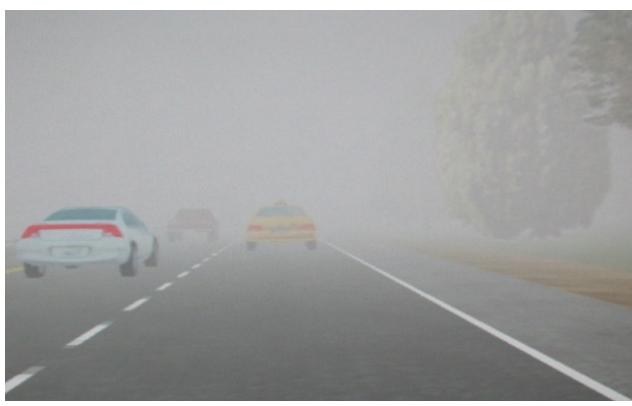

(b)

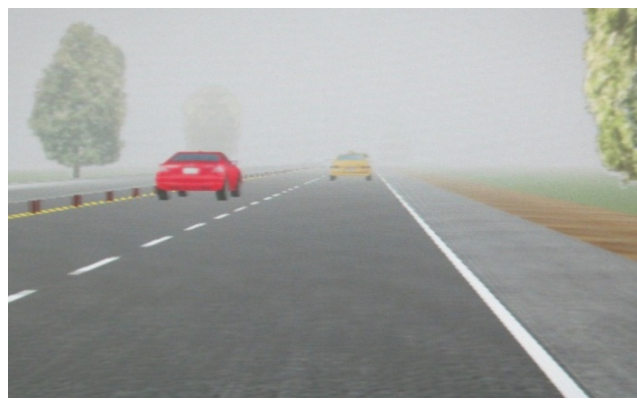

(d)

Figure 4 Visibility Distance (a) 65.62ft, (b) 164ft, (c) 328ft, and (d) 656.2ft. 


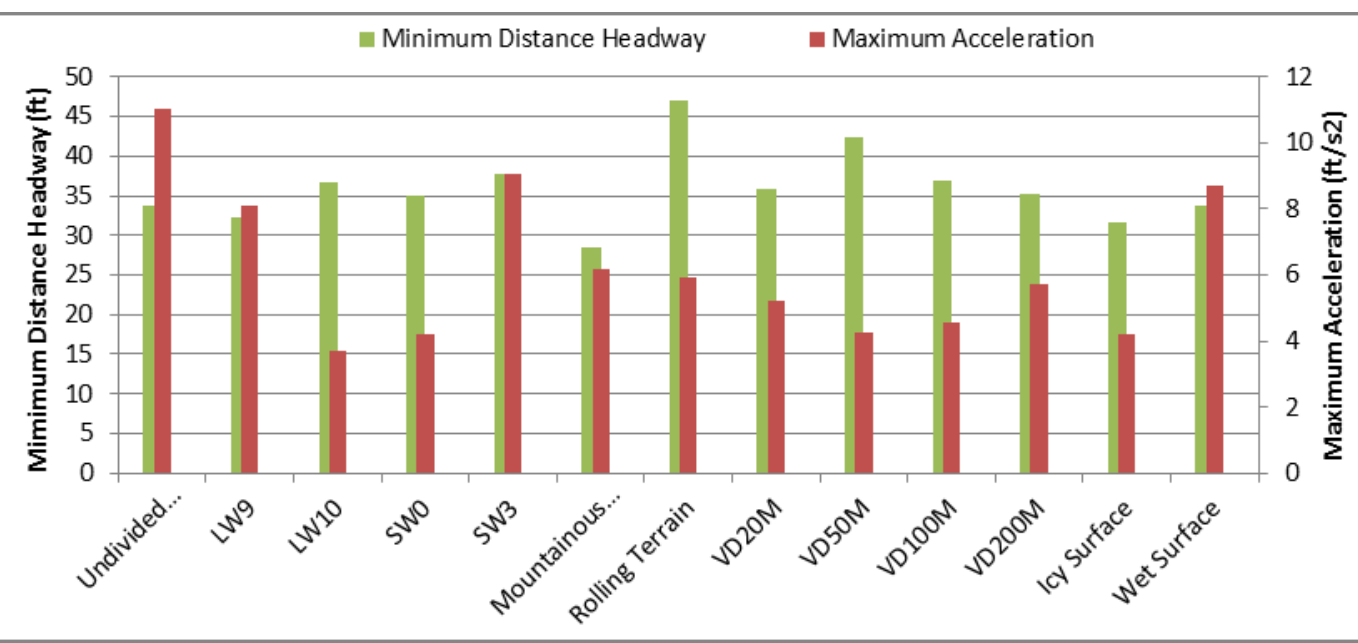

Figure 6 Maximum Acceleration and Minimum Distance Headway of the Follower. 


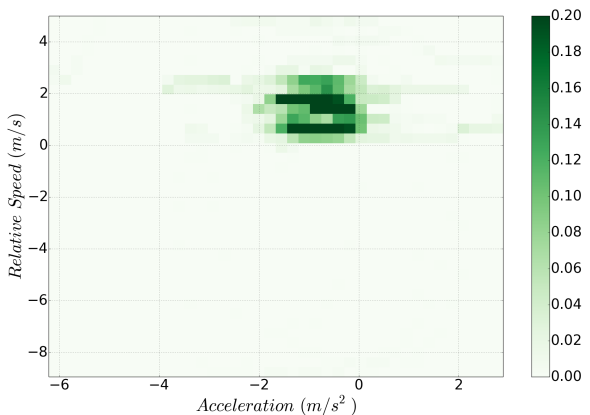

(a)

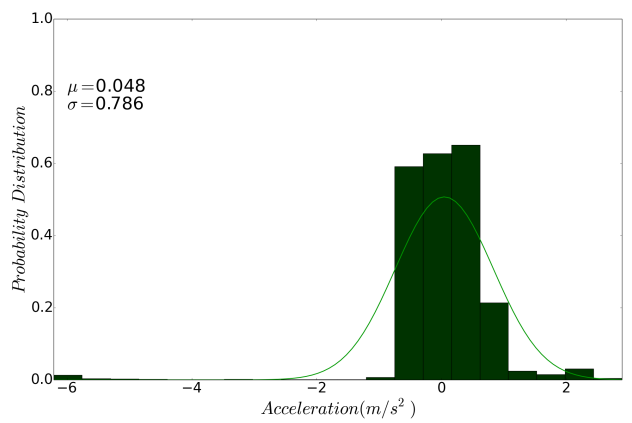

(c)

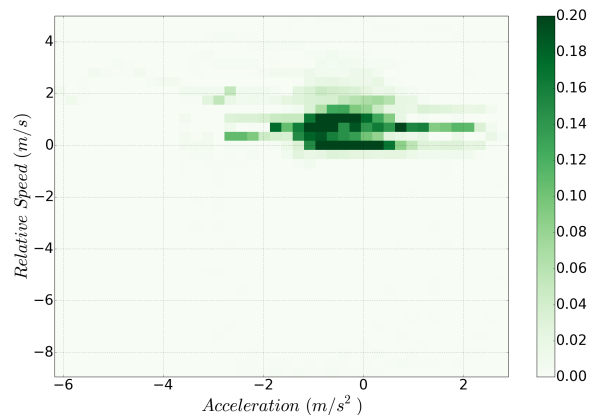

(b)

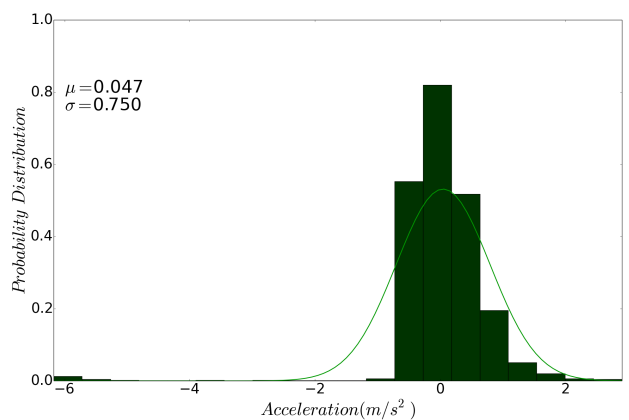

(d)
29

30

31

32

33

34

35

36

37

38

39

40

41

42

43

44

45

46

47

48

49

50

51

52

53

54

55

56

57

58

59

60

61

62

63

64

65

Figure 7 Two Examples of Drivers' Acceleration behavior in Moderately Challenging (a), and Extremely Challenging (b) driving conditions. 


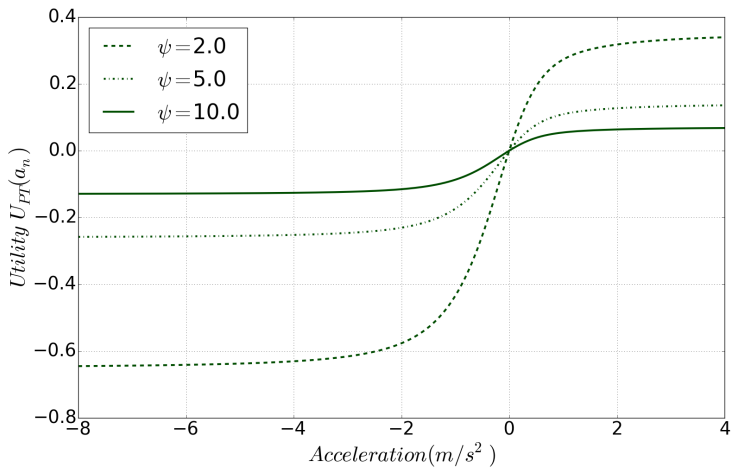

(a)

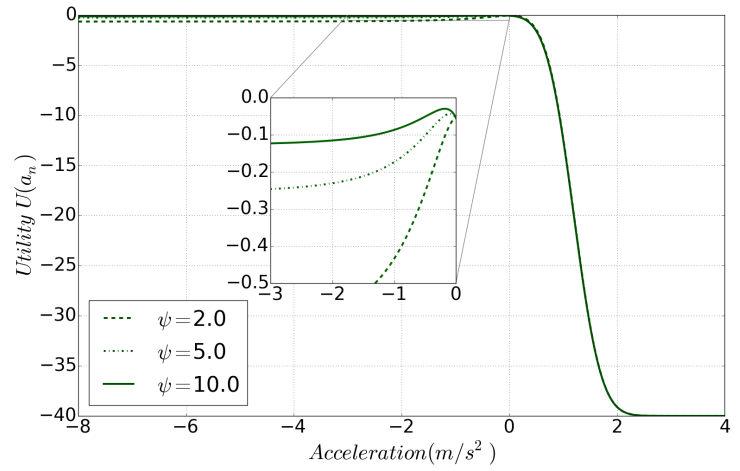

(c)

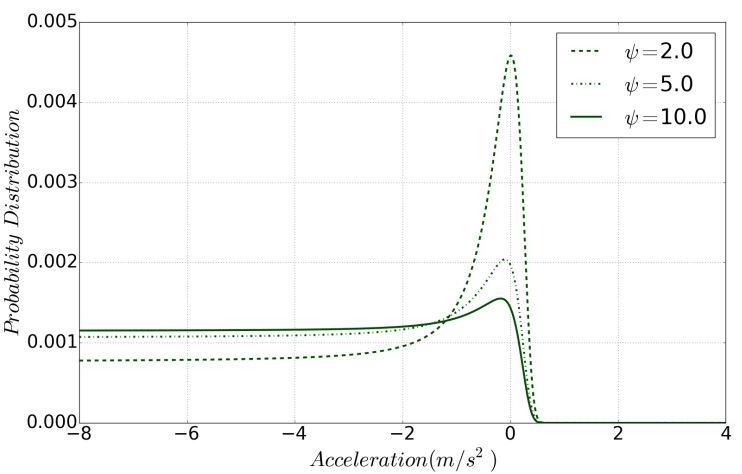

(e)

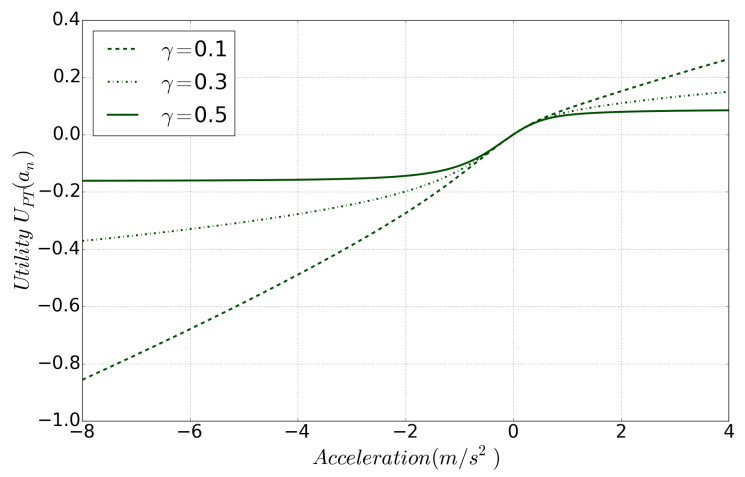

(b)

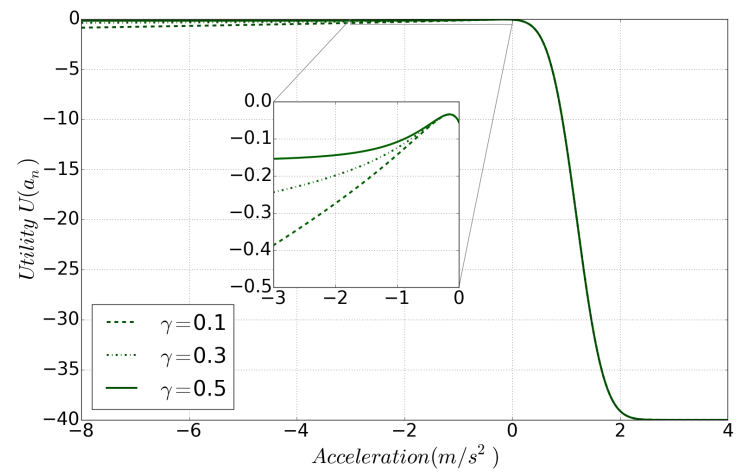

(d)

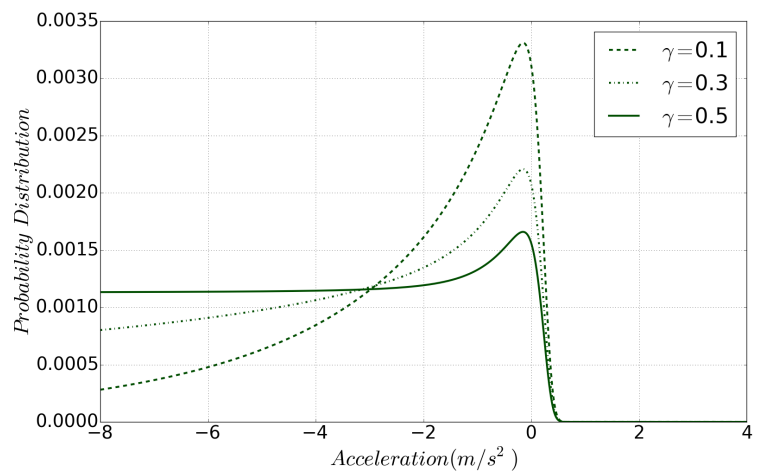

(f)

Figure 8 (a) Value Functions (Equation 3.2) for Different Values of $\psi$, (b) Value Functions (Equation 3.2) for Different Values of $\gamma$, (c) Utility Functions (Equation 3.3) for Different Values of $\psi$ and (d) Utility Functions (Equation 3.3) for Different Values of $\gamma$, (e) Probability Density Functions (Equation 3.4) for Different Values of $\psi$ and (f) Probability Density Functions (Equation 3.4) for Different Values of $\gamma$. 


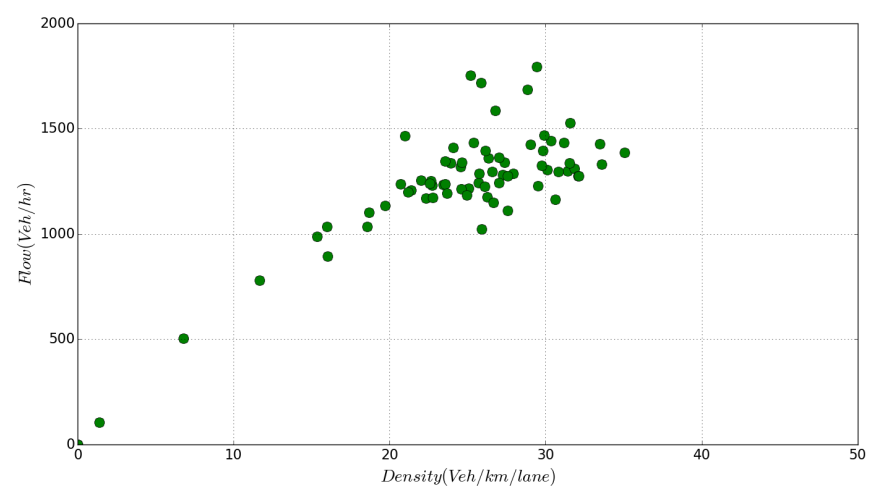

(a)

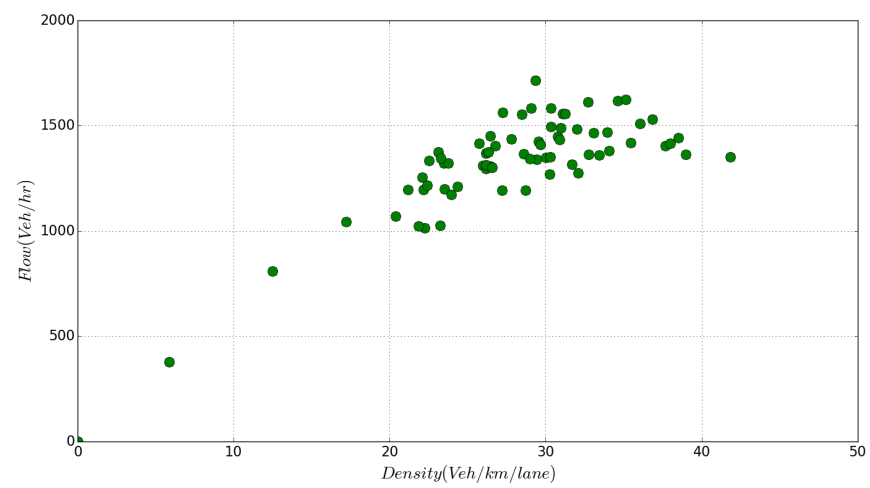

(b)

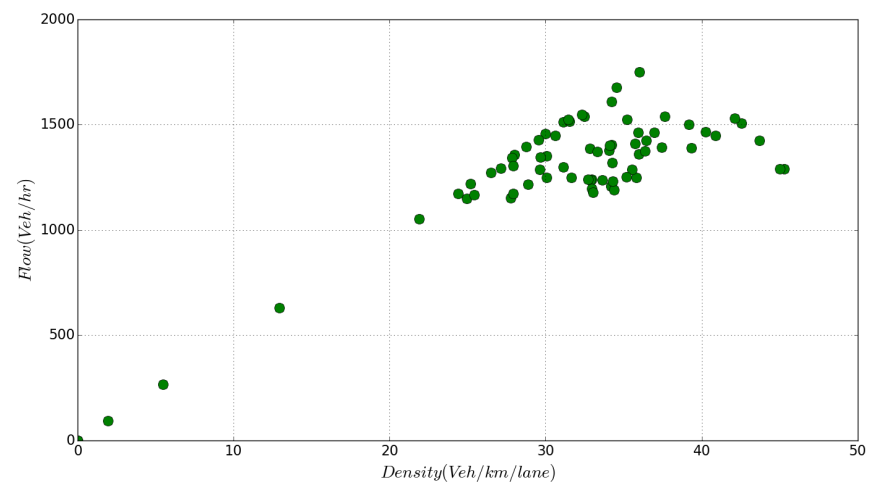

(c)

50

51

52 
Table 1 Main Events Used in the Driving Experiments

\begin{tabular}{|c|c|c|}
\hline Event Abbreviation & Event & Event Description \\
\hline A & Approaching Vehicle & Define oncoming traffic \\
\hline $\mathrm{V}$ & Following Vehicle & Define traffic in the direction of the driver \\
\hline BLDG & Buildings & Display buildings \\
\hline BSAV & Dynamic Data & Begin saving dynamic data for the output file \\
\hline $\mathrm{R}$ & Road & Display a specific roadway \\
\hline $\mathrm{C}$ & Road Horizontal Curve & $\begin{array}{l}\text { Add horizontal curves at desired location with desired length, } \\
\text { curvature, and radius }\end{array}$ \\
\hline VC & Road Vertical Curve & $\begin{array}{l}\text { Add vertical curves at desired location with desired length, } \\
\text { curvature, and radius }\end{array}$ \\
\hline ES & End Simulation & Call the simulation to stop \\
\hline JBAR & Jersey Barrier & Add desired barriers as the road median \\
\hline FOG & Fog & Add a patch of fog to simulation scene \\
\hline SIGN & Traffic Sign & Display a roadway sign \\
\hline TREE & Trees & Display trees on the side of the road \\
\hline RSA & Road Surface Attributes & Change the current road surface attributes \\
\hline
\end{tabular}


1

\begin{tabular}{lccc}
\hline Radius & $\boldsymbol{\alpha}_{\mathbf{1}}=\mathbf{1 0}$ degree & $\boldsymbol{\alpha}_{\mathbf{2}}=\mathbf{2 0}$ degree & $\boldsymbol{\alpha}_{3}=\mathbf{3 0}$ degree \\
\hline $984 \mathrm{ft}(300 \mathrm{~m})$ & $172 \mathrm{ft}$ & $345 \mathrm{ft}$ & $515 \mathrm{ft}$ \\
\hline $1968 \mathrm{ft}(600 \mathrm{~m})$ & $344 \mathrm{ft}$ & $687 \mathrm{ft}$ & $1030 \mathrm{ft}$ \\
\hline $3281 \mathrm{ft}(1000 \mathrm{~m})$ & $572 \mathrm{ft}$ & $1145 \mathrm{ft}$ & $1716 \mathrm{ft}$ \\
\hline
\end{tabular}


1

2

3

Table 3 Design of Vertical Curve Sections.

\begin{tabular}{lcccc}
\hline Type & Stop Sight Distance (ft) & Upgrade & Downgrade & $\begin{array}{c}\text { Vertical Curve Length } \\
\text { (ft) }\end{array}$ \\
\hline Simple Upgrade I & - & $3 \%$ & - & 500 \\
\hline Simple Upgrade II & - & $4 \%$ & - & 300 \\
\hline Simple Upgrade III & - & $5 \%$ & - & 200 \\
\hline Simple Downgrade I & - & - & $-3 \%$ & 500 \\
\hline Simple Downgrade II & - & - & $-4 \%$ & 300 \\
\hline Simple Downgrade III & - & - & $-5 \%$ & 200 \\
\hline Curve I & 150 & $4 \%$ & $-4 \%$ & 134 \\
\hline Curve II & 400 & $4 \%$ & $-4 \%$ & 963 \\
\hline Curve III & 400 & $4 \%$ & $-4 \%$ & 843 \\
\hline
\end{tabular}

4

5 
50

51

52
1

2

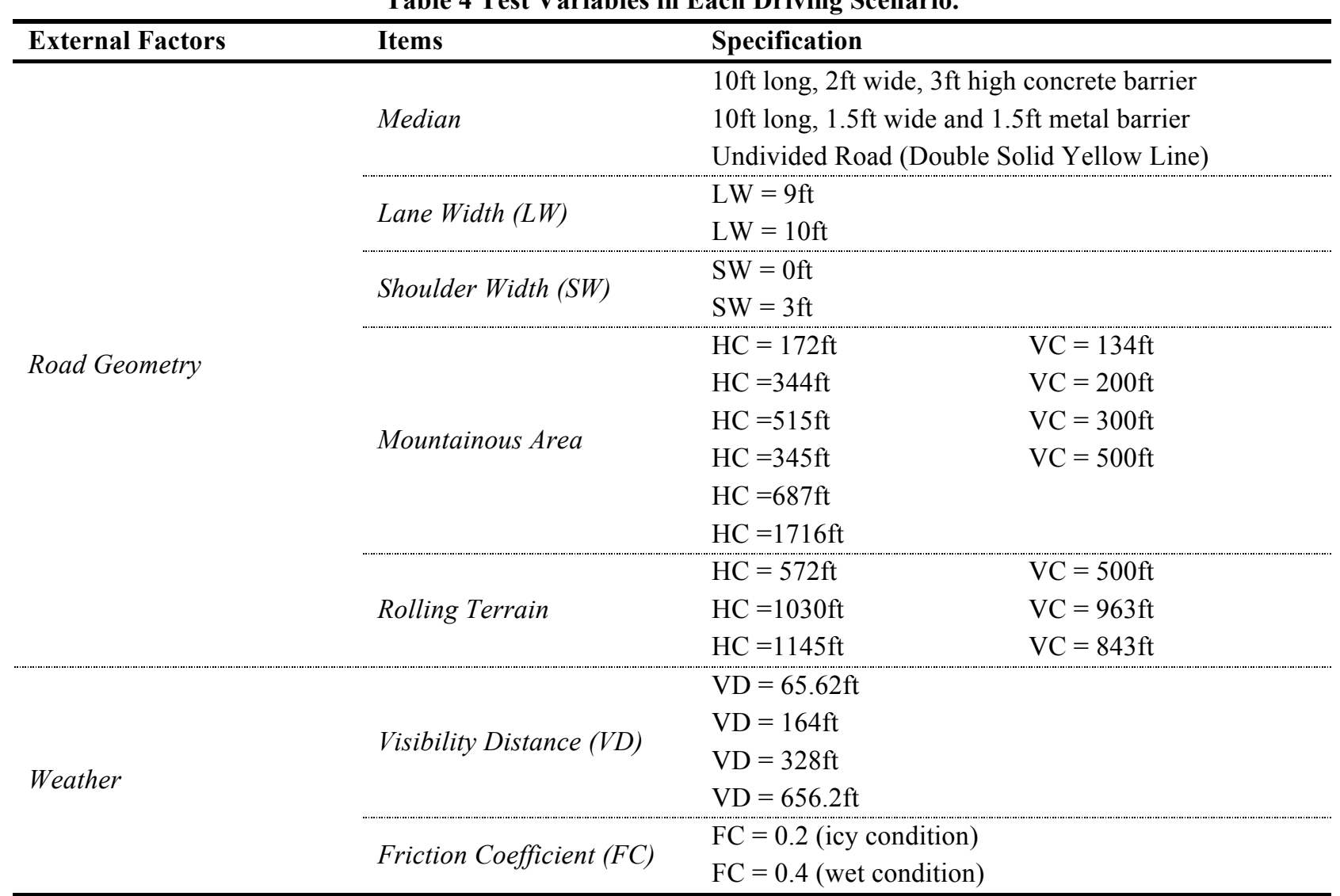


1

\begin{tabular}{|c|c|c|c|c|c|c|c|}
\hline \multirow{2}{*}{$\begin{array}{l}\text { External } \\
\text { Factors }\end{array}$} & \multirow{2}{*}{ Specification } & \multicolumn{6}{|c|}{ Driver Performance } \\
\hline & & $\mathbf{V}_{\text {ave }}$ & StdV & Delta $_{\text {ave }}$ & StdDeltaV & $\mathbf{T H}_{\text {ave }}$ & StdTH \\
\hline \multirow{9}{*}{$\begin{array}{l}\text { Roadway } \\
\text { Layouts }\end{array}$} & Standard Scenario & 23.87 & 10.10 & -2.78 & 12.00 & 4.92 & 6.95 \\
\hline & Jersey Barrier & 24.06 & 10.68 & -0.01 & 9.39 & 8.26 & 7.73 \\
\hline & Undivided Road & 24.22 & 10.66 & -0.14 & 7.24 & 4.72 & 6.58 \\
\hline & $\mathrm{LW}=9 \mathrm{ft}$ & 23.92 & 11.16 & -0.25 & 9.80 & 6.02 & 7.54 \\
\hline & $\mathrm{LW}=10 \mathrm{ft}$ & 24.08 & 10.57 & -0.06 & 8.14 & 6.17 & 9.06 \\
\hline & $\mathrm{SW}=0 \mathrm{ft}$ & 23.89 & 10.20 & -0.08 & 7.80 & 6.28 & 7.22 \\
\hline & $\mathrm{SW}=3 \mathrm{ft}$ & 23.73 & 11.35 & -0.10 & 10.77 & 9.42 & 18.10 \\
\hline & Mountainous & 24.07 & 9.90 & 0.16 & 7.39 & 4.05 & 6.86 \\
\hline & Rolling Terrain & 24.29 & 10.79 & -0.09 & 9.00 & 10.14 & 8.46 \\
\hline \multirow{6}{*}{ Weather } & $\mathrm{VD}=65.62 \mathrm{ft}$ & 24.19 & 11.24 & -0.34 & 9.80 & 8.07 & 7.98 \\
\hline & $\mathrm{VD}=164 \mathrm{ft}$ & 24.00 & 11.01 & -0.23 & 9.25 & 6.53 & 6.70 \\
\hline & $\mathrm{VD}=328 \mathrm{ft}$ & 24.20 & 10.04 & 0.01 & 9.03 & 6.27 & 6.71 \\
\hline & $\mathrm{VD}=656.2 \mathrm{ft}$ & 24.44 & 10.60 & -0.04 & 7.88 & 5.46 & 7.19 \\
\hline & Wet Surface & 23.94 & 10.31 & -0.14 & 7.84 & 6.10 & 6.62 \\
\hline & Icy Surface & 23.82 & 10.25 & -0.21 & 7.87 & 5.68 & 6.93 \\
\hline
\end{tabular}


Table 6 Experiment Sample

\begin{tabular}{ccc}
\hline Case & Value Label & $\mathbf{N}$ \\
\hline 1 & Normal Conditions & 11 \\
2 & Moderate Conditions & 14 \\
3 & Extreme Conditions & 19 \\
\hline
\end{tabular}

2 
Table 7 Descriptive Statistics of the Calibrated Parameters of the Extended Prospect Theory Based Acceleration Model

\begin{tabular}{|c|c|c|c|}
\hline Parameters & Case & Mean & Std. Deviation \\
\hline \multirow[t]{4}{*}{$\Psi(\psi)$} & Normal Conditions & 8.00 & 2.75 \\
\hline & Moderate Conditions & 6.54 & 3.26 \\
\hline & Extreme Conditions & 9.07 & 3.48 \\
\hline & Total & 7.87 & 3.35 \\
\hline \multirow[t]{4}{*}{$\gamma$} & Normal Conditions & 0.16 & 0.08 \\
\hline & Moderate Conditions & 0.14 & 0.11 \\
\hline & Extreme Conditions & 0.14 & 0.08 \\
\hline & Total & 0.15 & 0.09 \\
\hline \multirow[t]{4}{*}{$W_{m}\left(w^{-}\right)$} & Normal Conditions & 5.67 & 3.76 \\
\hline & Moderate Conditions & 6.67 & 3.97 \\
\hline & Extreme Conditions & 7.22 & 3.27 \\
\hline & Total & 6.66 & 3.59 \\
\hline \multirow[t]{4}{*}{$W_{c}\left(w_{c}\right)$} & Normal Conditions & 97181.82 & 26407.64 \\
\hline & Moderate Conditions & 78071.43 & 21585.12 \\
\hline & Extreme Conditions & 69052.63 & 20416.42 \\
\hline & Total & 78954.55 & 24618.91 \\
\hline \multirow[t]{4}{*}{$\alpha$} & Normal Conditions & 0.14 & 0.20 \\
\hline & Moderate Conditions & 0.08 & 0.12 \\
\hline & Extreme Conditions & 0.07 & 0.08 \\
\hline & Total & 0.09 & 0.13 \\
\hline \multirow[t]{4}{*}{$\beta$} & Normal Conditions & 5.52 & 2.66 \\
\hline & Moderate Conditions & 7.38 & 3.22 \\
\hline & Extreme Conditions & 5.67 & 3.51 \\
\hline & Total & 6.18 & 3.26 \\
\hline \multirow[t]{4}{*}{$\tau_{\max }$} & Normal Conditions & 6.01 & 1.94 \\
\hline & Moderate Conditions & 7.13 & 2.35 \\
\hline & Extreme Conditions & 6.81 & 1.99 \\
\hline & Total & 6.71 & 2.09 \\
\hline \multirow[t]{4}{*}{$\tau_{\text {corr }}$} & Normal Conditions & 21.91 & 6.38 \\
\hline & Moderate Conditions & 17.79 & 3.95 \\
\hline & Extreme Conditions & 21.74 & 5.29 \\
\hline & Total & 20.52 & 5.43 \\
\hline \multirow[t]{4}{*}{$R T$} & Normal Conditions & 1.09 & 0.92 \\
\hline & Moderate Conditions & 1.45 & 0.73 \\
\hline & Extreme Conditions & 1.40 & 0.85 \\
\hline & Total & 1.34 & 0.82 \\
\hline
\end{tabular}


Table 8 Data Sample of MANOVA Test

\begin{tabular}{lccccc}
\hline \multirow{2}{*}{ Case } & \multicolumn{5}{c}{ Parameters } \\
& $\mathrm{DV}_{1}$ & $\mathrm{DV}_{2}$ & $\ldots$ & $\mathrm{DV}_{9}$ & Mean \\
\hline $\mathrm{IV}_{1}$ & $x_{11}$ & $x_{12}$ & $\ldots$ & $x_{19}$ & $\overline{x_{1}}$ \\
\hline $\mathrm{IV}_{2}$ & $x_{21}$ & $x_{22}$ & $\ldots$ & $x_{29}$ & $\overline{x_{2}}$ \\
\hline $\mathrm{IV}_{3}$ & $x_{31}$ & $x_{32}$ & $\ldots$ & $x_{33}$ & $\overline{x_{3}}$ \\
\hline Mean & $\overline{x_{1}}$ & $\overline{x_{.2}}$ & $\ldots$ & $\overline{x_{.9}}$ & $\bar{x}$ \\
\hline
\end{tabular}


Table 9 Multivariate Tests

\begin{tabular}{lccccc}
\hline Effect & Value & F & Hypo. df & Error df & $\boldsymbol{p}$-value \\
\hline Pillai's Trace & .791 & 2.473 & 18 & 68.000 & .004 \\
\hline Wilks' Lambda & .350 & $2.531 \mathrm{~b}$ & 18 & 66.000 & .003 \\
\hline Hotelling's Trace & 1.453 & 2.584 & 18 & 64.000 & .003 \\
\hline Roy's Largest Root & 1.079 & $4.078 \mathrm{c}$ & 9 & 34.000 & .001 \\
\hline
\end{tabular}


Table 10 Cross Comparison of Dependent and Independent Variables.

\begin{tabular}{|c|c|c|c|c|c|c|c|}
\hline \multirow[t]{2}{*}{$\overline{D V s}$} & \multirow[t]{2}{*}{ (I) Case } & \multirow[t]{2}{*}{ (J) Case } & \multirow[t]{2}{*}{ Mean Difference (I-J) } & \multirow{2}{*}{$\begin{array}{c}\text { Std. } \\
\text { Error }\end{array}$} & \multirow[t]{2}{*}{ p-value } & \multicolumn{2}{|c|}{ 95\% Confidence Interval } \\
\hline & & & & & & Lower Bound & Upper Bound \\
\hline \multirow{3}{*}{$\begin{array}{l}\Psi \\
(\psi)\end{array}$} & $\mathrm{NC}$ & $\mathrm{MC}$ & 1.4643 & 1.3074 & 0.5070 & -1.7149 & 4.6435 \\
\hline & $\mathrm{NC}$ & $\mathrm{EC}$ & -1.0684 & 1.2294 & 0.6630 & -4.0579 & 1.9211 \\
\hline & $\mathrm{MC}$ & $\mathrm{EC}$ & -2.5327 & 1.1429 & 0.0800 & -5.3119 & 0.2465 \\
\hline \multirow{3}{*}{$\gamma$} & $\mathrm{NC}$ & $\mathrm{MC}$ & 0.0279 & 0.0369 & 0.7310 & -0.0618 & 0.1177 \\
\hline & $\mathrm{NC}$ & $\mathrm{EC}$ & 0.0215 & 0.0347 & 0.8100 & -0.0628 & 0.1059 \\
\hline & $\mathrm{MC}$ & $\mathrm{EC}$ & -0.0064 & 0.0323 & 0.9790 & -0.0848 & 0.0721 \\
\hline \multirow{3}{*}{$\begin{array}{l}W m \\
\left(w^{-}\right)\end{array}$} & $\mathrm{NC}$ & $\mathrm{MC}$ & -0.9987 & 1.4597 & 0.7740 & -4.5483 & 2.5509 \\
\hline & $\mathrm{NC}$ & $\mathrm{EC}$ & -1.5483 & 1.3726 & 0.5030 & -4.8861 & 1.7894 \\
\hline & $\mathrm{MC}$ & $\mathrm{EC}$ & -0.5496 & 1.2761 & 0.9030 & -3.6526 & 2.5534 \\
\hline \multirow{3}{*}{$\begin{array}{l}W_{c} \\
\left(w_{c}\right)\end{array}$} & $\mathrm{NC}$ & $\mathrm{MC}$ & 19110.3896 & 9016.7356 & 0.0980 & -2815.1637 & 41035.9429 \\
\hline & $\mathrm{NC}$ & $\mathrm{EC}$ & 28129.1866 & 8478.6592 & 0.0050 & 7512.0474 & 48746.3258 \\
\hline & $\mathrm{MC}$ & $\mathrm{EC}$ & 9018.7970 & 7882.3524 & 0.4930 & -10148.3322 & 28185.9262 \\
\hline \multirow{3}{*}{$\alpha$} & $\mathrm{NC}$ & $\mathrm{MC}$ & 0.0573 & 0.0538 & 0.5420 & -0.0736 & 0.1882 \\
\hline & $\mathrm{NC}$ & $\mathrm{EC}$ & 0.0657 & 0.0506 & 0.4050 & -0.0574 & 0.1888 \\
\hline & $\mathrm{MC}$ & $\mathrm{EC}$ & 0.0084 & 0.0471 & 0.9830 & -0.1060 & 0.1229 \\
\hline \multirow{3}{*}{$\beta$} & $\mathrm{NC}$ & $\mathrm{MC}$ & -1.8604 & 1.3009 & 0.3350 & -5.0238 & 1.3030 \\
\hline & $\mathrm{NC}$ & $\mathrm{EC}$ & -0.1502 & 1.2233 & 0.9920 & -3.1249 & 2.8244 \\
\hline & $\mathrm{MC}$ & $\mathrm{EC}$ & 1.7102 & 1.1373 & 0.3000 & -1.0553 & 4.4756 \\
\hline \multirow{3}{*}{$\tau_{\max }$} & $\mathrm{NC}$ & $\mathrm{MC}$ & -1.1195 & 0.8456 & 0.3900 & -3.1758 & 0.9368 \\
\hline & $\mathrm{NC}$ & $\mathrm{EC}$ & -0.7962 & 0.7952 & 0.5800 & -2.7298 & 1.1374 \\
\hline & $\mathrm{MC}$ & $\mathrm{EC}$ & 0.3233 & 0.7393 & 0.9000 & -1.4743 & 2.1209 \\
\hline \multirow{3}{*}{$\tau_{\text {corr }}$} & $\mathrm{NC}$ & $\mathrm{MC}$ & 4.1234 & 2.0992 & 0.1340 & -0.9812 & 9.2279 \\
\hline & $\mathrm{NC}$ & $\mathrm{EC}$ & 0.1722 & 1.9739 & 0.9960 & -4.6277 & 4.9722 \\
\hline & $\mathrm{MC}$ & $\mathrm{EC}$ & -3.9511 & 1.8351 & 0.0920 & -8.4135 & 0.5112 \\
\hline \multirow{3}{*}{$R T$} & $\mathrm{NC}$ & $\mathrm{MC}$ & -0.3591 & 0.3347 & 0.5360 & -1.1728 & 0.4547 \\
\hline & $\mathrm{NC}$ & $\mathrm{EC}$ & -0.3091 & 0.3147 & 0.5920 & -1.0743 & 0.4561 \\
\hline & $\mathrm{MC}$ & $\mathrm{EC}$ & 0.0500 & 0.2926 & 0.9840 & -0.6614 & 0.7614 \\
\hline
\end{tabular}

2

3

4

5

6 